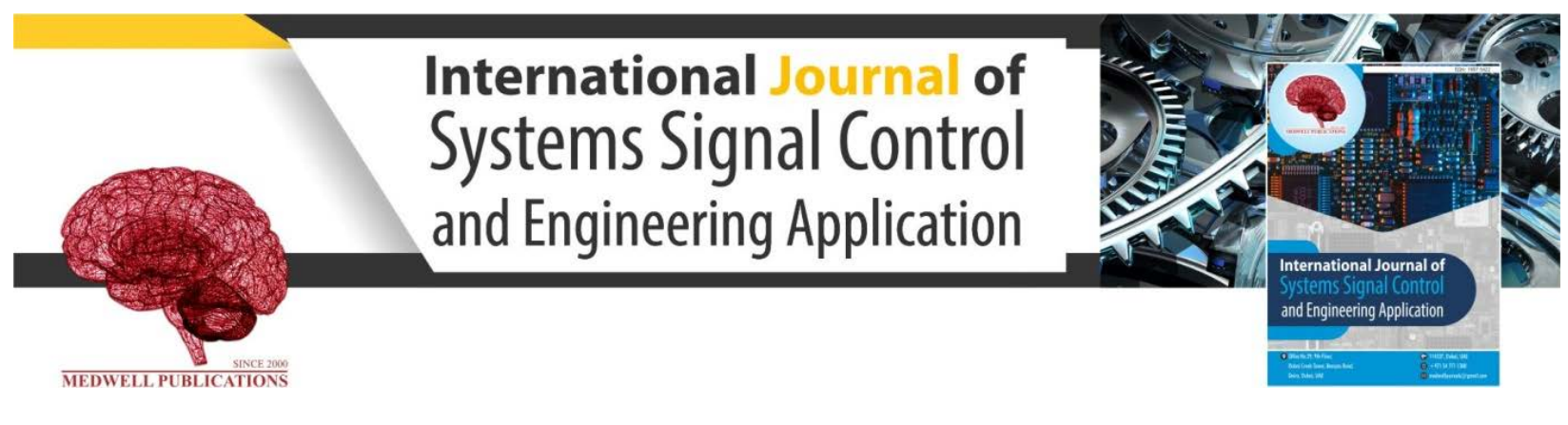

\title{
Distributed Model Predictive Control Based on New Cooperative Optimization Strategy for Nonlinear Large Scale Uncertain Systems
}

\author{
Ahmad Mirzaei and Amin Ramezani \\ Center of Advanced Control Systems, School of Electrical and Computer Engineering, Tarbiat Modares \\ University, Tehran, Iran
}

Key words: Cooperative optimization strategy, distributed extended dynamic matrix control, distributed adaptive generalized predictive control, equilibrium, trajectory

\section{Corresponding Author:}

Amin Ramezani

Center of Advanced Control Systems, School of Electrical and Computer Engineering, Tarbiat Modares University, Tehran, Iran

Page No.: 1-17

Volume: 13, Issue 1, 2020

ISSN: 1997-5422

International Journal of Systems Signal Control and Engineering Application

Copy Right: Medwell Publications
Abstract: In this study two linear cooperative Distributed constrained Model Predictive Control (DMPC) approaches are proposed to control the uncertain nonlinear interconnected large scale systems. In these approaches a proposed novel cooperative optimization strategy is employed that its advantage is to improve the centralized global cost function of each local controllers which decreases the control efforts, cost function values and convergence time compared to typical cooperative DMPCs which is demonstrated via. simulation results of a typical nonlinear large scale system. In proposed approaches two reconstructed linear distributed constrained model predictive controllers; Distributed Extended Dynamic Matrix Control (DEDMC) and Adaptive Generalized Predictive Control (DAGPC) are presented to control the uncertain nonlinear large scale systems by compensation of the mismatch between linearized and nonlinear models. The advantage of proposed controllers is their less complexity compared to fully nonlinear DMPCs. In DEDMC, the mismatch between linearized and nonlinear models is considered as a disturbance and in DAGPC this mismatch is compensated using online identification of the linearized model. The typical linear algorithms like distributed DMC leads to an unstable closed-loop response if the reference trajectory is a little far from the equilibrium point while this problem will be partially solved using the proposed DEDMC and will be completely solved using the proposed DAGPC even if the reference trajectory is too far from the equilibrium point. The performance of proposed approaches are demonstrated through simulation of a typical uncertain nonlinear large scale system. 


\section{INTRODUCTION}

Most industrial systems have nonlinear dynamic. A precise model of the simplest systems such as a DC motor is still nonlinear. On the other hand, many industrial systems are large scale systems which consist of a number of nonlinear subsystems. Control design for these nonlinear large scale systems is one of the important challenges. Model Predictive Control (MPC) is one of the desirable approaches for researchers to design the control algorithm for linear and nonlinear large scale systems that lead them to distributed MPC (DMPC) algorithms. Different linear DMPC approaches like cooperative, non-cooperative and agent negotiation are theoretically investigated in some papers that could be extended to nonlinear large scale systems ${ }^{[1,2]}$. Dual mode DMPC method is designed based on the proximity of the state variables to the origin. When the state variables are far from the origin the nonlinear DMPC algorithm is considered and on the other hand when the state variables are in origin's neighborhood, the linear DMPC algorithm is applied. Unlike the methods which use nonlinear algorithms when the states are in a neighborhood of the origin, the complexity of the computations is reduced using proposed dual mode DMPC method ${ }^{[3]}$. Gradient projection optimizer is designed as a subsidiary nonlinear nonconvex algorithm that improves the objective function and does not require a coordination layer ${ }^{[4,5]}$. On the contrary, some methods require coordination between their subsystems because each subsystem is optimized independently ${ }^{[6-8]}$. In these methods each subsystem exchanges its information to its interconnected neighbours via. coordinators. In some other approaches the interconnection between subsystems is considered as a constraint in each local optimization instead of using the coordinator $^{[9,10]}$. The network based DMPC algorithm with multirate sampling is a combination approach which is designed for a nonlinear large scale uncertain system composed of coupled subsystems. Local controllers are interconnected through a network based coordination structure that uses iterative strategy to control the entire large scale system ${ }^{[11]}$. The key factor in approaches with coordination layer or approaches in which each local controller optimizes its cost function separately and exchanges information to its neighbours is communication delay. In most of these approaches, communication delay is considered as a constraint ${ }^{[12,13]}$.

A two-layer robust DMPC strategy is another method which is designed for nonlinear constrained systems coupled through cost functions. Each subsystem receives information of control trajectories of its neighbours and solves its local optimization that involves interconnected coupling terms and computes its local optimal control signal. Sufficient conditions for convergence of states of all subsystems are provided in the first layer. In the second layer, robust DMPC approach is developed which uses a shorter prediction horizon and also tolerates larger disturbances ${ }^{[14]}$. Robust DMPC is a useful method to control a group of nonlinear subsystems subject to constraints of the control input and external disturbances $^{[15,16]}$.

Another DMPC approach for constrained large scale systems is sequential nonlinear DMPC strategy. In this approach each local MPC solves its own optimization problem and at each sampling time exchanges its information via. the communication channel to achieve the global objective of the overall system. The performance of the proposed nonlinear DMPC strategies is similar to the centralized nonlinear MPC but they are more efficient compared to the centralized approach ${ }^{[17]}$. By applying the contraction theory in DMPC algorithms, larger sampling intervals and stronger coupling between subsystems are addressed. The conservative conditions are also reduced using contraction theory ${ }^{[18]}$. Hierarchical base DMPC is a useful algorithm for uncertain large scale systems. A two level DMPC approach based on hierarchical framework is designed which takes inaccurate fault information into account to the system. The objective is compensating the identified actuator faults of the subsystems which include the detected time delays and uncertainties. In first level, the faults are recovered to maintain the design characteristics for all subsystems. In the second level, the recovery process is applied by increasing the whole system performance. The presented distributed method satisfies the recovery design characteristics via lower fault compensation and so, lower cost compared to the centralized and decentralized methods ${ }^{[19]}$.

The nonlinear large scale systems could be controlled via both linear and nonlinear DMPC algorithms. The linear algorithms are less complicated than nonlinear ones and the design's cost is lower. However there are restrictions to apply the linear algorithms for nonlinear systems if the nonlinearity degree is high or it has several equilibrium points then the closed loop nonlinear system may be unstable by applying linear algorithms. In this manuscript, a novel cooperative DMPC strategy is proposed which reduces the computational burden of optimization process and convergence time due to its main algorithm's reconfiguration. Moreover, to exploit the advantages of linear algorithms for controlling the constraint nonlinear systems two reconstructed linear algorithms are proposed based on Dynamic Matrix Control (DMC) and Generalized Predictive Control (GPC) methods. If the reference trajectory deviates too close to the equilibrium point then the nonlinear system could be controlled by linear algorithms. However, there are many nonlinear industrial plants with high degree of 
nonlinearity which could not be controlled using linear algorithms like DMC, moreover if the reference trajectory deviates farther away from the equilibrium point so these plants may be unstable. These problems will be partially solved using the proposed distributed linear algorithms; Distributed Extended Dynamic Matrix Control (DEDMC) and Distributed Adaptive Generalized Predictive Control (DAGPC).

Problem statement: mathematical models for nonlinear large scale systems: Consider a large scale system with nonlinear dynamic whose centralized model is decomposed into $\mathrm{M}$ coupled subsystems where subsystem i can be implemented by the following first order nonlinear continuous-time input-output model:

$$
\dot{y}_{i}(t)=f_{i}\left(y_{i}, u_{i}, u_{j}\right), \quad i=1,2, \ldots, M
$$

where $\mathrm{f}^{\mathrm{i}}$ is a nonlinear function, $\mathrm{y}_{\mathrm{i}} \in \mathrm{R}^{\text {nyi }}$ and $\mathrm{u}_{\mathrm{i}} \in \mathrm{R}^{\text {nui }}$ present the vectors of outputs and inputs of subsystem $\mathrm{i}$ respectively and $u_{j}(t)(j=1,2, \ldots ., M, J, \neq i)$ is the vector of inputs of the subsystem $\mathrm{j}$ which is the neighboring subsystem of subsystem $i$. It is assumed that $f_{i} i$ is Lipschitz function. The $M$ sets of subsystem's control inputs are constrained to be in $\mathrm{M}$ convex sets $\mathrm{U}_{\mathrm{i}} \in \mathrm{R}^{\mathrm{Mu}}{ }_{\mathrm{i}}, \mathrm{i}=1, \ldots, \mathrm{M}$ which are expressed as:

$$
\mathrm{U}_{\mathrm{i}}=\left\{\mathrm{u}_{\mathrm{i}} \in \mathrm{R}^{\mathrm{n}_{\mathrm{u}_{\mathrm{i}}}}:\left|\mathrm{u}_{\mathrm{i}}\right| \leq \mathrm{u}_{\mathrm{i}}^{\operatorname{Max}}\right\}
$$

where, $\mathrm{u}_{\mathrm{i}}^{\max }, \mathrm{I}, \ldots, \mathrm{M}$ are the constraint's magnitudes of the subsystem's inputs. The nonlinear continuous-time model of subsystem i can be discretized using Euler derivative approximation with sampling time $\mathrm{T}_{\mathrm{s}}$ :

$$
y_{i}(k+1)=g_{i}\left(y_{i}(k), u_{i}(k), u_{j}(k)\right), i=1,2, \ldots, M
$$

where, $g_{i}$ is a nonlinear function. In current manuscript a new cooperative optimization strategy is proposed. Moreover, two reconstructed distributed linear constrained algorithms; DEDMC and DAGPC are proposed to employ the proposed cooperative optimization strategy and control the nominal uncertain nonlinear large scale system of Eq. 1.

Approach; proposed cooperative optimization strategy: DMPC methods are divided into two main groups, cooperative and non-cooperative, based on communication structure between local controllers. Unlike the non- cooperative, in cooperative DMPC the same centralized global cost function which is defined based on a combination of all subsystem's cost functions, is optimized in each local controller to consider the effect of each local controller's input on the entire plant. Each local controller optimizes its control input by minimizing the global cost function at each iteration supposing that the other subsystem's control inputs of are equal to their last optimal values ${ }^{[1,20,4]}$. In the proposed cooperative DMPC strategy the global cost function will be modified. Each local controller optimizes the global cost function which is defined based on a convex combination of its own and its neighbor's cost functions. This proposed approach assumes that if based on equation 1 two subsystems are not neighbors, it is not necessary to consider their cost functions in each other's corresponding global cost functions. The effect of each local controller's input is still taken into account on the entire plant which is mathematically provable. The proposed idea helps us significantly reduce the computational burden of optimization processes of all subsystems. The proposed cooperative DMPC uses the following strategy. At time k, all the local Scontrollers receive the information of overall large scale system of Eq. 3.

At iteration p: Each local controller i calculates its own vector of future input $U_{+i}$ along the control horizon based on the input vectors of its neighboring Slocal controllers (not all other controllers) which are constant and equal to their latest optimal input vectors. When $\mathrm{p}=$ 1 , the initial guesses for all local controller's inputs, obtained from latest optimal control inputs are used). The neighboring local controllers exchange their input vectors and each local controller i calculates the current optimal input vector $\mathrm{U}_{+\mathrm{i}}^{\mathrm{opt}}$. According to receding horizon criteria the: current optimal control input $u_{+i}^{\text {optp }^{p}}$ is the first element of the current optimal input vector.

If a termination error condition considered in corresponding global cost function is satisfied in current iteration, each controller i dispatches its optimal control input $\mathrm{u}_{\mathrm{i}}^{\text {opt }}=\mathrm{u}_{+\mathrm{i}}^{\text {opp }}$ to its actuators; if not satisfied, go to step 2 and let $\mathrm{p}+1 \rightarrow \mathrm{p}$.

All subsystem's models are updated using obtained optimal control inputs. Whenever the control inputs of all local controllers are obtained, go to step 1 and let $\mathrm{k}+1 \rightarrow \mathrm{k}$. Each local controller i optimizes following optimization process at each iteration:

$$
\begin{aligned}
& \Delta \mathrm{u}_{\mathrm{i}}(\mathrm{k}), \ldots, \min _{\Delta \mathrm{u}_{\mathrm{i}}}(\mathrm{k}+\mathrm{m}-1) \mathrm{J}^{(\mathrm{k})} \\
& \text { futureinput vector }=\mathrm{u}_{+\mathrm{i}}=\left[\Delta \mathrm{v}_{\mathrm{i}}(\mathrm{k}), \ldots, \Delta \mathrm{u}_{\mathrm{i}}(\mathrm{k}+\mathrm{m}-1)\right]^{\mathrm{T}}
\end{aligned}
$$

Subject to Eq. 3:

$$
\mathrm{u}_{\mathrm{i}}(\mathrm{k}+\mathrm{j}) \in \mathrm{U}_{\mathrm{i}}, \mathrm{j}=0, \ldots ., \mathrm{m}-1
$$




$$
\begin{gathered}
\mathrm{U}_{+1}^{\mathrm{p}}=\mathrm{U}_{+\mathrm{i}}^{\mathrm{p}-1} \forall \mathrm{l} \in \mathrm{L} \text { and } \mathrm{l} \neq \mathrm{i} \\
\left\|\hat{\mathrm{y}}_{\mathrm{i}}(\mathrm{k}+\mathrm{p})-\mathrm{W}(\mathrm{k}+\mathrm{p})\right\|_{\mathrm{Q}_{\mathrm{i}}}^{2} \in \frac{\mathrm{p}}{\mathrm{k}} \mathrm{y}_{\mathrm{t}}
\end{gathered}
$$

With:

$$
\begin{gathered}
J(k)=\alpha_{\mathrm{i}} \mathrm{J}_{\mathrm{i}}+\sum_{1} \alpha_{\mathrm{i}} \mathrm{J}_{\mathrm{i}} \\
\alpha_{\mathrm{i}}, \alpha_{1}>0, \alpha_{\mathrm{i}}+\sum_{1} \alpha_{1}=1
\end{gathered}
$$

And:

$$
\mathrm{J}_{\mathrm{i}}(\mathrm{k})=\sum_{\mathrm{j}=1}^{\mathrm{p}}\left[\left\|\hat{\mathrm{y}}_{\mathrm{i}}(\mathrm{k}+\mathrm{j})-\mathrm{W}(\mathrm{k}+\mathrm{j})\right\|_{\mathrm{Q}_{\mathrm{i}}}\right]+\sum_{\mathrm{j}=1}^{\mathrm{m}}\left\|\Delta \mathrm{u}_{\mathrm{i}}(\mathrm{k}+\mathrm{j}-1)\right\|_{\mathrm{R}_{\mathrm{i}}}^{2}
$$

Where:

$\mathrm{m}$ and $\mathrm{p}=$ Control and prediction horizons, respectively $\mathrm{L} \subset \mathrm{M} \quad=$ The set of neighboring subsystems of subsystem i .

Equation 7 denotes the termination error condition in which $\mathrm{y}_{\mathrm{t}}$ is the symmetric closed set in the neighborhood of origin. The termination error condition states that if the closed loop system is stable, then the prediction error tends to zero over the time $\hat{y}_{i}(\mathrm{k}+\mathrm{j}), \mathrm{j}=1, \ldots, \mathrm{p}$ is the subsystem's i predicted output that in each linear MPC algorithm is calculated via. particular manner. $\mathrm{W}$ is the reference trajectory. $\mathrm{Q}_{\mathrm{i}}$ and $\mathrm{R}_{\mathrm{i}}$ and diagonal positive definite weighting matrices of prediction errors and control inputs respectively with appropriate dimensions. To achieve global optimality, $\mathrm{J}(\mathrm{k})$ is presented as a convex combination of subsystem $i$ and its neighbor's cost functions with appropriate $\alpha_{\mathrm{i}}$ and $\alpha_{\mathrm{i}}$ coefficients.

Approach; proposed cooperative constrained DMPC algorithms: There are two key reasons for using linear algorithms to control the nonlinear large scale systems. First, the identification of a linear subsystem based on empirical data is much easier than nonlinear one. Second, most of the industrial nonlinear systems like liquid level control, internal temperature control of a furnace and pressure control have only one equilibrium point, thus they can be identified by a precise linear model and then linear DMPCs can be employed to control the linearized system and determine the subsystem's optimal control inputs. In this manuscript two reconstructed constrained distributed linear algorithms; DEDMC and DAGPC are proposed to control the uncertain nonlinear large scale systems. These algorithms are distinguished via how the nonlinear model is applied in optimization process. In
DEDMC the linearized version of nominal nonlinear model is taken into account and the mismatch between linearized and nonlinear models is considered as a constraint and will be compensated. So, the predicted outputs calculated via both models are similar to each other. The DAGPC algorithm identifies the numerator and denominator polynomials of the linearized system's transfer function which actually presents the nonlinear behavior of the plant.

\section{MATERIALS AND METHODS}

Proposed cooperative constrained DEDMC algorithm: In fact, EDMC is the extended version of the DMC algorithm that takes the nonlinear model into account, so, this algorithm also uses the system's step response to determine the predicted outputs similar to $\mathrm{DMC}^{[21]}$. The predicted output of the subsystem i in distributed DMC algorithm is represented as follows:

$$
\begin{aligned}
\hat{y}_{\mathrm{i}}(\mathrm{k}+\mathrm{j}) & =\sum_{\mathrm{q}=1}^{\mathrm{N}} \mathrm{g}_{\mathrm{i}_{\mathrm{q}}} \Delta \mathrm{u}_{\mathrm{i}}(\mathrm{k}+\mathrm{j}-\mathrm{q})+\sum_{\mathrm{l}} \sum_{\mathrm{q}=1}^{\mathrm{N}} \mathrm{g}_{\mathrm{iiq}} \Delta \mathrm{u}_{\mathrm{i}}(\mathrm{k}+\mathrm{j}-\mathrm{q})+\hat{\mathrm{n}}_{\mathrm{i}}(\mathrm{k}+\mathrm{j}) \\
\mathrm{i} & =1, \ldots, \mathrm{M}, \mathrm{l} \in \mathrm{L}, \mathrm{l} \neq \mathrm{i}
\end{aligned}
$$

Where:

$\mathrm{g}_{\mathrm{iq}}$ and $\mathrm{g}_{\mathrm{ilq}}=$ The step response coefficients of subsystem i and its interconnected neighboring subsystem

l, $\mathrm{N} \quad=$ The model horizon

$\Delta \mathrm{u}_{\mathrm{i}}$ and $\Delta \mathrm{u}_{\mathrm{i}}=$ The increment control inputs of subsystems i and l, respectively

An integrator should be added to remove the steady state error so increment of control inputs are used instead of control input in DMC and so in EDMC methods. $\hat{n}_{i}(k+j)$ is the estimation of the future time disturbances assuming that disturbance and other signals of plant, until time $\mathrm{j}$ are presented. In distributed DMC, $\hat{\mathrm{n}}_{\mathrm{i}}(\mathrm{k}+\mathrm{j})$ is considered as external disturbances applied to the system. Moreover, it is assumed that the future disturbance is constant along the prediction horizon and equal to the current disturbance $\hat{\mathrm{n}}_{\mathrm{i}}(\mathrm{k})$. The disturbance is defined as difference between measured and predicted outputs:

$$
\begin{aligned}
& \hat{\mathrm{n}}_{\mathrm{i}}(\mathrm{k}+\mathrm{j})=\hat{\mathrm{n}}_{\mathrm{i}}(\mathrm{k})=\mathrm{y}_{\mathrm{m}_{\mathrm{i}}}(\mathrm{k})-\sum_{\mathrm{q}=1}^{\mathrm{N}} \mathrm{g}_{\mathrm{iq}} \Delta \mathrm{u}_{\mathrm{i}}(\mathrm{k}-\mathrm{q})- \\
& \sum_{\mathrm{i}} \sum_{\mathrm{q}=1}^{\mathrm{N}} \mathrm{g}_{\mathrm{ilq}} \Delta \mathrm{u}_{\mathrm{i}}(\mathrm{k}-\mathrm{q})
\end{aligned}
$$

where, the $\mathrm{y}_{\mathrm{mi}}(\mathrm{k})$ is the measured output. The cost function of subsystem $\mathrm{i}$ in distributed DMC is: 
Int. J. Syst. Signal Control Eng. Appl., 13 (1): 1-17, 2020

$$
J_{i}(k)=\sum_{j=1}^{p}\left\|\hat{y}_{i}(k+j)-W(k+j)\right\|\left\|_{Q_{i}}^{2}+\sum_{j=1}^{m}\right\| \Delta u_{i}(k+j-1) \|_{R_{i}}^{2}
$$

And also the cost function is represented as the matrix form of:

$$
J_{t}=\left(Y_{i}-W\right)^{T} Q_{i}\left(Y_{i}-W\right)+U_{+_{i}}{ }^{T} R_{i} U_{t_{i}}
$$

In which the elements of the $y_{i}$ is obtained using Eq. 11 and 12 and series characteristics:

$$
\begin{gathered}
\mathrm{Y}_{\mathrm{i}}=\mathrm{G}_{\mathrm{i}} \mathrm{U}_{+_{\mathrm{i}}}+\sum_{\mathrm{l} \neq \mathrm{i}} \mathrm{G}_{\mathrm{il}} \mathrm{U}_{\mathrm{t}_{\mathrm{i}}}+\text { Free response }_{\mathrm{i}} \\
\text { Free respone } \mathrm{e}_{\mathrm{i}}=\mathrm{H}_{\mathrm{i}} \mathrm{U}_{-\mathrm{i}}+\sum_{\mathrm{l} \neq \mathrm{i}} \mathrm{H}_{\mathrm{il}} \mathrm{U}_{-\mathrm{l}}+\mathrm{Y}_{\mathrm{m}_{\mathrm{i}}}(\mathrm{k}) \mathrm{I}_{\mathrm{p} \times 1}
\end{gathered}
$$

Where:

$\mathrm{y}_{\mathrm{i}} \quad=$ The predicted outputs vector

$\mathrm{U}_{+\mathrm{i}}$ and $\mathrm{U}_{+\mathrm{l}}=$ The future control inputs vectors

$\mathrm{U}_{-\mathrm{i}}$ and $\mathrm{U}_{+1}=$ The determined past control inputs vectors of subsystems $i$ and l, respectively

According to cooperative optimization strategy proposed in section 3 the future control inputs vector of neighboring subsystem $\mathrm{l}$ in iteration $\mathrm{p}$ is constant and equal to its latest optimal value. $G_{i}, G_{i l}, H_{i}$ and $H_{i l}$ are MPC matrices with appropriate dimensions:

$$
\begin{aligned}
& \mathrm{Y}_{\mathrm{i}}=\left[\begin{array}{c}
\hat{\mathrm{y}}_{\mathrm{i}}(\mathrm{k}+1) \\
\hat{\mathrm{y}}_{\mathrm{i}}(\mathrm{k}+2) \\
\vdots \\
\hat{\mathrm{y}}_{\mathrm{i}}(\mathrm{k}+\mathrm{p})
\end{array}\right] \\
& \mathrm{U}_{+\mathrm{i}}\left[\begin{array}{c}
\Delta \mathrm{u}_{\mathrm{i}}(\mathrm{k}) \\
\Delta \mathrm{u}_{\mathrm{i}}(\mathrm{k}+1) \\
\vdots \\
\Delta \mathrm{u}_{\mathrm{i}}(\mathrm{k}+\mathrm{m}-1)
\end{array}\right], \mathrm{U}_{-\mathrm{i}}=\mathrm{U}_{+1}^{\mathrm{p}-1} \\
& \mathrm{U}_{-\mathrm{i}}\left[\begin{array}{c}
\Delta \mathrm{u}_{\mathrm{i}}(\mathrm{k}-1) \\
\Delta \mathrm{u}_{\mathrm{i}}(\mathrm{k}-2) \\
\vdots \\
\Delta \mathrm{u}_{\mathrm{i}}(\mathrm{k}-\mathrm{N})
\end{array}\right] \mathrm{mU}_{-\mathrm{l}}=\left[\begin{array}{c}
\Delta \mathrm{u}_{\mathrm{i}}(\mathrm{k}-1) \\
\Delta \mathrm{u}_{\mathrm{i}}(\mathrm{k}-2) \\
\vdots \\
\Delta \mathrm{u}_{\mathrm{i}}(\mathrm{k}-\mathrm{N})
\end{array}\right] \\
& \mathrm{G}_{\mathrm{i}}=\left[\begin{array}{ccccc}
\mathrm{g}_{\mathrm{i}} & 0 & & \cdots & 0 \\
\mathrm{~g}_{\mathrm{i}} & \mathrm{g}_{\mathrm{i} 1} & & \cdots & 0 \\
\vdots & \vdots & & \ddots & \vdots \\
\mathrm{g}_{\text {ii }} & \mathrm{g}_{\mathrm{i}}(\mathrm{m}-1) & \cdots & & \mathrm{g}_{\text {i1 }} \\
\vdots & \vdots & \ddots & & \vdots \\
\mathrm{g}_{\text {ip }} & \mathrm{g}_{\mathrm{i}}(\mathrm{p}-1) & \cdots & & \mathrm{g}_{\mathrm{i}}(\mathrm{p}-\mathrm{m}+1)
\end{array}\right]_{p^{*} \mathrm{~m}}
\end{aligned}
$$

$$
\begin{aligned}
& \mathrm{G}_{\text {il }}=\left[\begin{array}{ccccc}
\mathrm{g}_{\text {ill }} & 0 & & \cdots & 0 \\
\mathrm{~g}_{\text {ill }} & \mathrm{g}_{\text {ii }} & & \cdots & 0 \\
\vdots & \vdots & & \ddots & \vdots \\
\mathrm{g}_{\text {illm }} & \mathrm{g}_{\text {ill }}(\mathrm{m}-1) & \cdots & & \mathrm{g}_{\text {ill } 1} \\
\vdots & \vdots & \ddots & & \vdots \\
\mathrm{g}_{\text {ilp }} & \mathrm{g}_{\text {il }}(\mathrm{p}-1) & \cdots & & \mathrm{g}_{\text {il }}(\mathrm{p}-\mathrm{m}+1)
\end{array}\right]_{\mathrm{p}^{*} \mathrm{~m}} \\
& \mathrm{H}_{\mathrm{i}}=\left[\begin{array}{ccc}
\mathrm{g}_{\mathrm{i}}-\mathrm{g}_{\mathrm{i}} & \cdots & \mathrm{g}_{\mathrm{i}}(\mathrm{N}+1)-\mathrm{g}_{\mathrm{iN}} \\
\vdots & \ddots & \vdots \\
\mathrm{g}_{\mathrm{i}}(\mathrm{p}+1)-\mathrm{g}_{i 1} & \cdots & \mathrm{g}_{\mathrm{il}}(\mathrm{N}+\mathrm{p})-\mathrm{g}_{\mathrm{iN}}
\end{array}\right]_{\mathrm{p}^{*} \mathrm{~N}} \\
& \mathrm{H}_{\mathrm{il}}=\left[\begin{array}{ccc}
\mathrm{g}_{\mathrm{il}}-\mathrm{g}_{\mathrm{il1}} & \cdots & \mathrm{g}_{\mathrm{il}}(\mathrm{N}+1)-\mathrm{g}_{\mathrm{iN}} \\
\vdots & \ddots & \vdots \\
\mathrm{g}_{\mathrm{il}}(\mathrm{p}+1)-\mathrm{g}_{\mathrm{ill}} & \cdots & \mathrm{g}_{\mathrm{il}}(\mathrm{N}+\mathrm{p})-\mathrm{g}_{\mathrm{iN}}
\end{array}\right]_{\mathrm{p}^{*} \mathrm{~N}}
\end{aligned}
$$

The closed form solution of optimal future control inputs vector of subsystem i could be analytically calculated by computing the following derivative (Eq. 17):

$$
\begin{aligned}
& \frac{\partial \mathrm{J}_{\mathrm{i}}}{\mathrm{U}_{+1}}=0 \rightarrow \mathrm{U}_{+\mathrm{i}}{ }^{\text {opt }}=\left(\mathrm{G}_{\mathrm{i}}{ }^{\mathrm{T}} \mathrm{Q}_{\mathrm{i}} \mathrm{G}_{\mathrm{i}}+\mathrm{R}_{\mathrm{i}}\right)^{-1} \\
& \mathrm{G}_{\mathrm{i}}^{\mathrm{T}} \mathrm{Q}_{\mathrm{i}}\left(\mathrm{W}-\sum_{\mathrm{i} \neq \mathrm{i}} \mathrm{G}_{\mathrm{ill}} \mathrm{U}_{+\mathrm{i}}-\text { FreeResponse }\right)
\end{aligned}
$$

It should be noted that the linear DMPC algorithms could have any limitations for example in distributed DMC algorithm, it must be considered that the nominal nonlinear system should not be unstable $\mathrm{e}^{[21]}$.

In EDMC algorithm the $\hat{n}_{i}(\mathrm{k}+\mathrm{j})$ consists of two part, one part is measurable or unmeasurable external disturbances similar to DMC and the other part is the disturbances due to the mismatch (uncertainty) between the linearized and nonlinear models which will be presented by mismatch disturbance matrix $\mathrm{D}_{\text {nli }}$. The objective of the proposed DEDMC algorithm is to compensate this mismatch.

In proposed DEDMC algorithm the disturbance matrix is added to free response to compensate the mismatch between linearized and nonlinear models. So, the prediction vector of subsystem $\mathrm{i}$ is reconstructed as:

$$
\mathrm{Y}_{\mathrm{i}}=\mathrm{G}_{\mathrm{i}} \mathrm{U}_{+\mathrm{i}}+\sum_{\mathrm{l} \neq \mathrm{i}} \mathrm{G}_{\mathrm{il}} \mathrm{U}_{+\mathrm{i}}+\text { Free Response } \mathrm{i}_{\mathrm{i}}+\mathrm{D}_{\mathrm{nl}_{\mathrm{i}}}
$$

where, Free Response ${ }_{\mathrm{i}}$ is presented in Eq. 16 and:

$$
\mathrm{D}_{\mathrm{nl}_{\mathrm{i}}}=\left[\begin{array}{c}
\mathrm{d}_{\mathrm{nl}_{\mathrm{i}}}(\mathrm{k}+1) \\
\mathrm{d}_{\mathrm{ni}_{\mathrm{i}}}(\mathrm{k}+2) \\
\vdots \\
\mathrm{d}_{\mathrm{nl}_{\mathrm{i}}}(\mathrm{k}+\mathrm{p})
\end{array}\right]
$$


where, $\mathrm{d}^{\mathrm{nli}} \in \mathrm{R}^{\text {ndil }}$. The mismatch between linearized and nonlinear models of all subsystems should be compensated. Thus, the following equation should be solved in which the predicted outputs of the linearized and nonlinear models must be equal to each other:

$$
Y_{\mathrm{i}}^{\text {linearized predictor }}=\mathrm{Y}_{\mathrm{i}}^{\text {linearized predictor }}
$$

The elements of $D_{\text {nli }}$ will be calculated via. solving Eq. 19 and so, the mismatch will be compensated. The proposed DEDMC algorithm solves the following optimization problem for subsystem $i$ at each iteration which has been established based on novel cooperative optimization strategy proposed in section 3 . At the first step, the vector of future control inputs which was calculated using distributed DMC algorithm (Eq. 17) is defined as a function of mismatch disturbance matrix $\mathrm{D}_{\mathrm{nli}}$ :

$$
\begin{gathered}
\mathrm{U}_{+\mathrm{i}}\left(\mathrm{D}_{\mathrm{nl}_{\mathrm{i}}}\right)=\left(\mathrm{G}_{\mathrm{i}}^{\mathrm{T}} \mathrm{Q}_{\mathrm{i}} \mathrm{G}_{\mathrm{i}}+\mathrm{R}_{\mathrm{i}}\right)^{-1} \mathrm{G}_{\mathrm{i}}{ }^{\mathrm{T}} \mathrm{Q}_{\mathrm{i}} \\
\left(\mathrm{W}-\sum_{\mathrm{l} \neq \mathrm{i}} \mathrm{G}_{\mathrm{ij}} \mathrm{U}_{+1}-\text { freeresponse }_{\mathrm{i}}-\mathrm{D}_{\mathrm{nl}_{\mathrm{i}}}\right) \\
\min _{\mathrm{D}_{\mathrm{nl}_{\mathrm{i}}}} \mathrm{j}(\mathrm{k}), \mathrm{i}=1,2, \ldots, \mathrm{M}
\end{gathered}
$$

Subject to Eq. 3 and 19:

$$
\begin{gathered}
\mathrm{u}_{\mathrm{i}}(\mathrm{k}+\mathrm{j}) \in \mathrm{U}_{\mathrm{i}}, \mathrm{j}=0, \ldots, \mathrm{m}-1 \\
\mathrm{U}_{+1}^{\mathrm{p}}\left(\mathrm{D}_{\mathrm{nl}_{\mathrm{i}}}\right)=\mathrm{U}_{+1}^{\mathrm{p}-1}\left(\mathrm{D}_{\mathrm{nl}_{\mathrm{i}}}\right), \forall \mathrm{l} \in \mathrm{L} \text { and } \mathrm{l} \neq \mathrm{i} \\
\left\|\hat{\mathrm{y}}_{\mathrm{i}}(\mathrm{k}+\mathrm{p})-\hat{\mathrm{y} N L_{\mathrm{i}}}(\mathrm{k}+\mathrm{p})\right\|_{\mathrm{Q}_{\mathrm{i}}}^{2} \in_{\mathrm{k}}^{\mathrm{p}} \mathrm{y}_{\mathrm{t}}
\end{gathered}
$$

With:

$$
\begin{gathered}
J(k)=\alpha_{i} J_{i}+\sum_{1} \alpha_{i} J_{i} \\
\alpha_{i}, \alpha_{1}>0, \alpha_{i}+\sum_{1} \alpha_{1}=1
\end{gathered}
$$

And:

$$
\mathrm{J}_{\mathrm{i}}(\mathrm{k})=\sum_{\mathrm{j}=1}^{\mathrm{p}}\left[\left\|\hat{\mathrm{y}}_{\mathrm{i}}(\mathrm{k}+\mathrm{j})-\hat{\mathrm{y}}_{\mathrm{NL}_{\mathrm{i}}}(\mathrm{k}+\mathrm{j})\right\|_{\mathrm{Q}_{\mathrm{i}}}^{2}+\left\|\mathrm{d}_{\mathrm{nl}_{\mathrm{i}}}(\mathrm{k}+\mathrm{j})\right\|_{\mathrm{R}_{\mathrm{i}}}^{2}\right]
$$

The cost function is represented as the matrix form of:

$$
\mathrm{J}_{\mathrm{i}}=\left(\mathrm{Y}_{\mathrm{i}}-\mathrm{Y}_{\mathrm{NL}_{\mathrm{i}}}\right)^{\mathrm{T}} \mathrm{Q}_{\mathrm{i}}\left(\mathrm{Y}_{\mathrm{i}}-\mathrm{Y}_{\mathrm{NL}_{\mathrm{i}}}\right)+\mathrm{D}_{\mathrm{nl}_{\mathrm{i}}}{ }^{\mathrm{T}} \mathrm{R}_{\mathrm{i}} \mathrm{D}_{\mathrm{nl}_{\mathrm{i}}}
$$

where, $\mathrm{Y}_{\mathrm{i}}$ is defined in Eq. 18 and $\mathrm{Y}_{\mathrm{NLi}}$ is the nonlinear prediction vector:

$$
\mathrm{Y}_{\mathrm{NL}_{\mathrm{i}}}=\left[\begin{array}{c}
\hat{\mathrm{y}}_{\mathrm{NL}_{\mathrm{i}}}(\mathrm{k}+1) \\
\hat{\mathrm{y}}_{\mathrm{NL}_{\mathrm{i}}}(\mathrm{k}+2) \\
\vdots \\
\hat{\mathrm{y}}_{\mathrm{NL}_{\mathrm{i}}}(\mathrm{k}+\mathrm{P})
\end{array}\right]
$$

By solving the optimization problem in Eq. 20-27 the mismatch between linearized an nonlinear models is compensated and the optimal control input trajectory $\mathrm{U}_{+\mathrm{i}}^{\text {opt }}\left(\mathrm{D}_{\mathrm{nl}_{\mathrm{i}}}\right)$ is obtained. The optimal control input is then calculated as:

$$
\mathrm{u}_{\mathrm{i}}^{\mathrm{opt}}(\mathrm{k})=\Delta \mathrm{u}_{\mathrm{i}}^{\text {opt }}(\mathrm{k})+\mathrm{u}_{\mathrm{i}}^{\text {opt }}(\mathrm{k}-1)
$$

where according to receding horizon criteria the optimal increment control input $\Delta_{\mathrm{ui}}^{\text {opt }}(\mathrm{k})$ is the first element of $\mathrm{U}_{+\mathrm{i}}^{\text {opt }}\left(\mathrm{D}_{\mathrm{nl}}\right)$. The order $\mathrm{U}_{+\mathrm{i}}^{\text {opt }}\left(\mathrm{D}_{\mathrm{nl}}\right)$ is $\mathrm{m} \times 1$ and the order of nonlinear prediction vector $\mathrm{Y}_{\mathrm{NLi}}$ is $\mathrm{P} \times 1$, so to calculate the $\mathrm{u}_{+\mathrm{i}}^{\mathrm{opt}}$ in the nonlinear prediction process in MATLAB, the control signal vector $\mathrm{U}_{+\mathrm{i}}^{\text {opt }}\left(\mathrm{D}_{\text {ni }}\right)$ is considered as follows:

$$
\mathrm{U}_{+\mathrm{i}}\left(\mathrm{D}_{\mathrm{nl}_{\mathrm{i}}}\right)=\left[\begin{array}{c}
\mathrm{U}_{+\mathrm{i}}\left(\mathrm{D}_{\mathrm{nl}_{\mathrm{i}}}\right) \\
0_{(\mathrm{p}-\mathrm{m}) \times 1}
\end{array}\right]
$$

Where the ${ }_{0(p-m) \times 1}$ id the zero column matrix in the proposed cooperative constrained DEDMC algorithm, the mismatch between linearized and nonlinear models is compensated, so if the reference trajectory moves farther away from the equilibrium point, the simulation results illustrate desirable effect of this algorithm while the system may be unstable using the distributed DMC algorithm. However, if the reference trajectory is farther away from the equilibrium point too much or the nonlinearity of the system is high, then the proposed cooperative DEDMC algorithm will also lead to an unstable response. This problem will be completely solved by the following proposed cooperative constrained ADGPC method.

Proposed cooperative constrained DAGPC algorithm The linear GPC algorithm is developed based on the transfer function model of the system which can be applied to unstable and non-minimum phase systems ${ }^{[21]}$. The mismatch between linearized and nonlinear models will be compensated using online identification approach in the proposed cooperative constrained DAGPC algorithm. The numerator and denominator polynomials of the linearized model will be identif ied using RLS algorithm and nonlinear large scale system's input 
and output information. The linearized model of each nonlinear subsystem is obtained using online identification in each time step and then by means of identified numerator and denominator polynomials, nominal nonlinear subsystem's free response and GPC algorithm, the vector of optimal control inputs will be calculated using the cooperative optimization strategy proposed in section 3. The calculated optimal control inputs will be applied to nonlinear system and this process moves to the next time step. The free response of the nominal nonlinear subsystem is derived from its past information of input and output. Suppose that the identified linearized model of subsystem i is:

$$
\mathrm{y}_{\mathrm{i}}(\mathrm{k})=\frac{\mathrm{B}_{\mathrm{ii}}^{\mathrm{I}}\left(\mathrm{z}^{-1}\right)}{A_{\mathrm{ii}}^{\mathrm{I}}\left(\mathrm{z}^{-1}\right)} \mathrm{u}_{\mathrm{i}}(\mathrm{k})+\sum_{\mathrm{i} \neq \mathrm{i}} \frac{\mathrm{B}_{\mathrm{il}}^{\mathrm{I}}\left(\mathrm{z}^{-1}\right)}{\mathrm{A}_{\mathrm{ii}}^{\mathrm{I}}\left(\mathrm{z}^{-1}\right)} \mathrm{u}_{\mathrm{i}}(\mathrm{k})
$$

The DAGPC matrices will be calculated using the new identified polynomials of the linearized model and finally theoptimal control input will be obtained using these new DAGPC matrices. The proposed DAGPC algorithm solves the following optimization problem for subsystem $i$ at each iteration which has been established based on novel cooperative optimization strategy proposed in section 3 in which the new identified numerator and denominator of linearized model of each subsystem is calculated in the beginning of each time step:

$$
\begin{aligned}
& \Delta \mathrm{u}_{\mathrm{i}}(\mathrm{k}), \ldots, \min _{\Delta \mathrm{ui}(\mathrm{k}+\mathrm{m}-1)} \mathrm{J}(\mathrm{k}) \\
& \mathrm{U}_{+\mathrm{i}}=\left[\Delta \mathrm{u}_{\mathrm{i}}(\mathrm{k}), \ldots, \Delta \mathrm{u}_{\mathrm{i}}(\mathrm{k}+\mathrm{m}-1)\right]^{\mathrm{T}}
\end{aligned}
$$

Subject to equation $30 \forall_{\mathrm{i}}=1, \ldots, \mathrm{M}$ and $\mathrm{l} \subset \mathrm{L}, \mathrm{l} \neq \mathrm{i}$ :

$$
\begin{gathered}
\mathrm{u}_{\mathrm{i}}(\mathrm{k}+\mathrm{j}) \in \mathrm{U}_{\mathrm{i}}, \mathrm{j}=0, \ldots, \mathrm{m}-1 \\
\mathrm{U}_{+\mathrm{i}}^{\mathrm{p}}=\mathrm{U}_{+\mathrm{i}}^{\mathrm{p}-1}, \forall \mathrm{l} \in \mathrm{L} \text { and } \mathrm{l} \neq \mathrm{i} \\
\left\|\hat{\mathrm{y}}_{\mathrm{i}}(\mathrm{k}+\mathrm{p})-\mathrm{W}(\mathrm{k}+\mathrm{p})\right\|_{\mathrm{Q}_{\mathrm{i}}}^{2} \in \frac{\mathrm{p}}{\mathrm{k}} \mathrm{y}_{\mathrm{t}}
\end{gathered}
$$

With:

$$
\begin{gathered}
J(k)=\alpha_{i} \mathrm{~J}_{\mathrm{i}}+\sum_{1} \alpha_{\mathrm{i}} \mathrm{J}_{\mathrm{i}} \\
\alpha_{\mathrm{i}}, \alpha_{1}>0, \alpha_{\mathrm{i}}+\sum_{1} \alpha_{1}=1
\end{gathered}
$$

And:

$$
\mathrm{J}_{\mathrm{i}}(\mathrm{k})=\sum_{\mathrm{j}=1}^{\mathrm{p}}\left\|\hat{\mathrm{y}}_{\mathrm{i}}(\mathrm{k}+\mathrm{j})-\mathrm{W}(\mathrm{k}+\mathrm{j})\right\|_{\mathrm{Q}_{\mathrm{i}}}^{2}+\sum_{\mathrm{j}=1}^{\mathrm{m}}\left\|\Delta \mathrm{u}_{\mathrm{i}}(\mathrm{k}+\mathrm{j}-1)\right\|_{\mathrm{R}_{\mathrm{i}}}^{2}
$$

The cost function is represented as the matrix form of:

$$
\mathrm{J}_{\mathrm{i}}=\left(\mathrm{Y}_{\mathrm{i}}-\mathrm{W}\right)^{\mathrm{T}} \mathrm{Q}_{\mathrm{i}}\left(\mathrm{Y}_{\mathrm{i}}-\mathrm{W}\right)+\mathrm{U}_{+\mathrm{i}}{ }^{\mathrm{T}} \mathrm{R}_{\mathrm{i}} \mathrm{U}_{+\mathrm{i}}
$$

Where the predicted output matrix form of:

$$
\mathrm{Y}_{-\mathrm{i}}=\phi_{\mathrm{i}}^{\mathrm{l}} \mathrm{Y}_{-\mathrm{t}}+\pi_{\mathrm{i}}^{\mathrm{l}} \mathrm{U}_{-\mathrm{i}}+\sum_{\mathrm{l} \neq \mathrm{i}} \pi_{\mathrm{il}}^{\mathrm{l}} \mathrm{U}_{-\mathrm{l}}+\Omega_{\mathrm{i}}^{\mathrm{l}} \mathrm{U}_{+\mathrm{i}}+\sum_{\mathrm{i} \neq \mathrm{i}} \Omega_{\mathrm{il}}^{\mathrm{l}} \mathrm{U}_{+1}
$$

The closed form solution of the vector of optimal future control inputs of subsystem i could be analytically calculated by computing the following derivative Eq. 41:

$$
\begin{aligned}
& \frac{\partial J_{i}}{U_{+i}}=\rightarrow U_{+i}^{o p t}=\left(\Omega_{1}^{1 T} Q_{i} \Omega_{i}^{1}+R_{i}\right)^{-1} \\
& G_{i}^{T} Q_{i}\left(W-\phi_{1}^{i} Y_{-1}-\pi_{1}^{1} U_{-i}-\sum_{I \neq 1} \pi_{i i}^{1} U_{-1} \sum_{i \neq 1} \Omega_{i i}^{i} U_{+1}\right)
\end{aligned}
$$

where:

$$
\begin{gathered}
\mathrm{Y}_{\mathrm{i}}=\left[\begin{array}{c}
\hat{\mathrm{y}}_{\mathrm{i}}(\mathrm{k}+1) \\
\hat{\mathrm{y}}_{\mathrm{i}}(\mathrm{k}+2) \\
\vdots \\
\hat{\mathrm{y}}_{\mathrm{i}}(\mathrm{k}+\mathrm{p})
\end{array}\right]_{\mathrm{p} \times 1}, \mathrm{Y}_{-\mathrm{i}}=\left[\begin{array}{c}
\hat{\mathrm{y}}_{\mathrm{i}}(\mathrm{k}) \\
\hat{\mathrm{y}}_{\mathrm{i}}(\mathrm{k}-2) \\
\vdots \\
\hat{\mathrm{y}}_{\mathrm{i}}\left(\mathrm{k}-\mathrm{n}_{\mathrm{a}_{\mathrm{i}}}^{\mathrm{I}}\right)
\end{array}\right]\left(\mathrm{n}_{\mathrm{ai}}^{\mathrm{I}}+1\right) \times 1 \\
\mathrm{U}_{+1}=\left[\begin{array}{c}
\Delta \mathrm{u}_{\mathrm{i}}(\mathrm{k}) \\
\Delta \mathrm{u}_{\mathrm{i}}(\mathrm{k}+1) \\
\vdots \\
\Delta \mathrm{u}_{\mathrm{i}}(\mathrm{k}+\mathrm{m}-1)
\end{array}\right]_{\mathrm{m} \times 1}, \mathrm{U}_{+1}=\mathrm{U}_{+1}^{\mathrm{p}-1}
\end{gathered}
$$

$$
\mathrm{U}_{-\mathrm{i}}=\left[\begin{array}{c}
\Delta \mathrm{u}_{\mathrm{i}}(\mathrm{k}-1) \\
\Delta \mathrm{u}_{\mathrm{i}}(\mathrm{k}-2) \\
\vdots \\
\Delta \mathrm{u}_{\mathrm{i}}\left(\mathrm{k}-\mathrm{n}_{\mathrm{b}_{\mathrm{i}}}^{\mathrm{I}}\right)
\end{array}\right]_{\mathrm{n}_{\mathrm{b}} \times 1} \quad \mathrm{U}-\mathrm{l}=\left[\begin{array}{c}
\Delta \mathrm{u}_{\mathrm{i}}(\mathrm{k}-1) \\
\Delta \mathrm{u}_{\mathrm{i}}(\mathrm{k}-2) \\
\vdots \\
\Delta \mathrm{u}_{\mathrm{i}}\left(\mathrm{k}-\mathrm{n}_{\mathrm{bu}}^{\mathrm{I}}\right)
\end{array}\right]
$$

in which $\mathrm{n}_{\mathrm{ai}}^{\mathrm{I}}, \mathrm{n}_{\mathrm{abi}}^{\mathrm{I}}$ and $\mathrm{n}_{\mathrm{ail}}^{\mathrm{I}}$ are the orders of the $\mathrm{A}_{\mathrm{ii}}^{\mathrm{I}}, \mathrm{B}_{\mathrm{ii}}^{\mathrm{I}}$ and $\mathrm{B}_{\mathrm{il}}^{\mathrm{I}}$ idetified polynomials, respectively. For calculating $\hat{\mathrm{y}}_{\mathrm{i}}(\mathrm{k}+\mathrm{j})(\mathrm{j}=1,2, \ldots, \mathrm{p})$ developed CARIMA and Diophantine relations are taken into account similar to the typical GPC algorithm in as following equations and assuming that the delay is zero:

$$
\Delta \mathrm{A}_{\mathrm{ii}}^{\mathrm{I}}\left(\mathrm{z}^{-1}\right) \mathrm{y}_{\mathrm{i}}(\mathrm{k})=\left[\begin{array}{c}
\mathrm{B}_{\mathrm{ii}}^{\mathrm{I}}\left(\mathrm{z}^{-1}\right) \Delta \mathrm{u}_{\mathrm{i}}(\mathrm{k}-1)+ \\
\sum_{\mathrm{l} \neq \mathrm{i}} \mathrm{B}_{\mathrm{il}}^{\mathrm{I}}\left(\mathrm{z}^{-1}\right) \Delta \mathrm{u}_{\mathrm{i}}(\mathrm{k}-1)
\end{array}\right]+\mathrm{C}_{\mathrm{i}}^{\mathrm{I}}\left(\mathrm{z}^{-1}\right) \mathrm{e}_{\mathrm{i}}(\mathrm{k})
$$


Int. J. Syst. Signal Control Eng. Appl., 13 (1): 1-17, 2020

$$
1=E_{i j}^{I}\left(z^{-1}\right) \Delta A_{i i}^{I}\left(z^{-1}\right)+z^{-j} F_{i j}^{1}\left(z^{-1}\right)
$$

where:

$$
\begin{gathered}
F_{i}^{I}\left(z^{-1}\right)=f_{i(j, 0)}+f_{i(j, 1)} z^{-1}+, \ldots, f_{i}\left(j, n_{a i}^{1}\right) z-n_{a_{i}}^{I} \\
E_{i}^{I}\left(z^{-1}\right) e_{i(j, 0)}+e_{i(j, 1)} z^{-1}+, \ldots ., e_{i(j, j-1)} z^{-(j-1)}
\end{gathered}
$$

where, the coefficients of $F_{i j}^{I}\left(z^{-1}\right)$ and $E_{i j}^{I}\left(z^{-1}\right)$ polynomials are calculated using the following recursive equations:

$$
\begin{gathered}
F_{i 1}^{I}=z\left(1-\Delta A_{i i}^{I}\left(z^{-1}\right)\right) \\
E_{i 1}^{I}=1 \\
E_{i j+1}^{I}\left(z^{-1}\right)=E_{i j}^{I}\left(z^{-1}\right)+f_{i(j, 0)} z^{-j} \\
f_{i(j+1, q)}=f_{i}(j, q+1)-f_{i(j, 0)}-f_{j, 0} \tilde{\alpha}_{(q+1)} q=0,1, \ldots, n_{a i}^{I}
\end{gathered}
$$

where, $\tilde{\alpha}_{i(q+1)}\left(q=0,1, \ldots, n_{a_{i}}^{1}\right)$ are the coefficients of the $\Delta \mathrm{A}_{\mathrm{ii}}^{\mathrm{L}}\left(\mathrm{z}^{-1}\right)$ polynomial. The future outputs are achieved using Eq. 41 and 42 :

$$
\begin{aligned}
& y_{i}(k+j)=F_{i j}^{I}\left(z^{-1}\right) y_{i}(k)+E_{i j}^{I}\left(z^{-1}\right)\left[\begin{array}{c}
B_{i i}^{I}\left(z^{-1}\right) \Delta u_{i}(k+j-1)+ \\
\sum_{i \neq 1} B_{i i}^{I}\left(z^{-1}\right) \Delta u_{i}(k+j-1)
\end{array}\right](42) \\
& +E_{i j}^{1}\left(z^{-1}\right) e_{i}(k+j)
\end{aligned}
$$

The proper estimation of $y_{i}(k+j)$ is its average so the predicted outputs are obtained using the average of $\mathrm{y}_{\mathrm{i}}(\mathrm{k}+\mathrm{j})$ in Eq. 49:

$$
\begin{gathered}
\tilde{y}_{i}(k+j)=G_{i}^{1}\left(z^{-1}\right) \Delta u_{i}(k+j-1)+\sum_{i \neq i} G_{i j}^{I}\left(z^{-1}\right) \Delta u_{i} \\
(k+j-1)+F_{i j}^{I}\left(z^{-1}\right) y_{i}(k), j=1, \ldots, p \\
G_{i i l}^{I}\left(z^{-1}\right)=B_{i l}^{I}\left(z^{-1}\right) E_{i j}^{I}\left(z^{-1}\right) \\
G_{i i l}^{I}\left(z^{-1}\right)=B_{i i l}^{I}\left(z^{-1}\right) E_{i j}^{I}\left(z^{-1}\right)
\end{gathered}
$$

Since, the $e_{i}(k+j)$ is the white noise, so its average is zero. The new DAGPC matrices in Eq. 39 are presented with appropriate dimensions as:

$$
\phi_{i}^{L}=\left[\begin{array}{ccc}
f_{i(0,1)} & \cdots & f_{i}\left(1, n_{a i}^{i}\right) \\
f_{i(2,1)} & \ddots & f_{i}\left(2, n_{a i}^{i}\right) \\
f_{i(p, 0)} & \vdots & f_{i}\left(p, n_{a i}^{i}\right)
\end{array}\right]_{p \times\left(n_{a}^{1}+1\right)}
$$

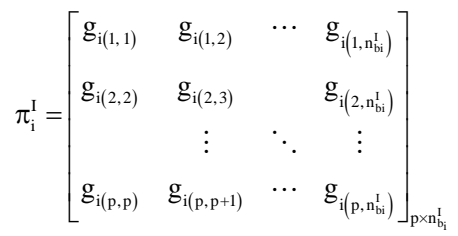

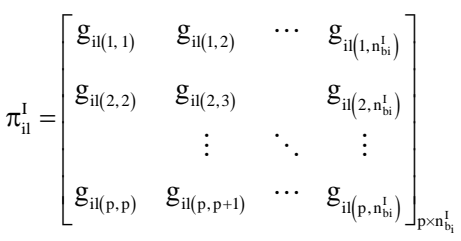

$$
\begin{aligned}
& \Omega_{\mathrm{i}}^{\mathrm{I}}=\left[\begin{array}{ccccc}
\mathrm{g}_{\mathrm{i}(1,0)} & 0 & 0 & & 0 \\
\mathrm{~g}_{\mathrm{i}(2,1)} & \mathrm{g}_{\mathrm{i}(2,0)} & 0 & \cdots & 0 \\
& \vdots & & \ddots & \vdots \\
\mathrm{g}_{\mathrm{il}(\mathrm{p}, \mathrm{p})} & \mathrm{g}_{\mathrm{i}(\mathrm{p}, \mathrm{p}-2)} & & \cdots & \mathrm{g}_{\mathrm{i}(\mathrm{p}, 0)}
\end{array}\right]_{\mathrm{p} \times \mathrm{p}} \\
& \Omega_{\mathrm{ill}}^{\mathrm{I}}=\left[\begin{array}{ccccc}
\mathrm{g}_{\mathrm{il}(1,0)} & 0 & 0 & & 0 \\
\mathrm{~g}_{\mathrm{il}(2,1)} & \mathrm{g}_{\mathrm{il}(2,0)} & 0 & \ldots & 0 \\
& \vdots & & \ddots & \vdots \\
\mathrm{g}_{\mathrm{il}(p, \mathrm{p})} & \mathrm{g}_{\mathrm{il}(\mathrm{p}, \mathrm{p}-2)} & & \ldots & \mathrm{g}_{\mathrm{il}(\mathrm{p}, 0)}
\end{array}\right]_{\mathrm{p} \times \mathrm{p}}
\end{aligned}
$$

where, $\mathrm{g}_{\mathrm{i}(\mathrm{j}, \mathrm{q})}$ and $\mathrm{g}_{\mathrm{i}(\mathrm{j}, \mathrm{q})}(\mathrm{j}=1,2, \ldots, \mathrm{p}, \mathrm{q}=1,2, . .$,$) are the$ coefficients of the $G_{i j}^{1}\left(z^{-1}\right)$ and $G_{i j}^{1}\left(z^{-1}\right)$ polynomials, respectively. Since, the GPC is developed based on transfer function model, it is possible to obtain the closed-loop transfer function and derive some properties such as stability.

\section{RESULTS AND DISCUSSION}

A typical nonlinear large scale system consisting of three coupled subsystems is employed as following input-output models to investigate the proposed approaches:

$$
\left\{\begin{array}{c}
\dot{y}_{1}(t)=-y_{1}(t)+y_{1}(t)^{2}+7 u_{1}(t)+4 u_{2}(t) \\
\dot{y}_{2}(t)=-3 y_{2}(t)+2 y_{2}(t)^{2}+10 u_{2}(t)+u_{3}(t)^{2} \\
\dot{y}_{3}(t)=-2 y_{3}(t)+y_{3}(t)^{2}+2 u_{3}(t)+u_{2}(t)
\end{array}\right.
$$

The subsystems are coupled trough inputs. The discrete-time system could be obtained using following Euler derivative approximation:

$$
\dot{y}_{\mathrm{i}}(\mathrm{t})=\frac{\mathrm{y}_{\mathrm{i}}(\mathrm{k}+1)-\mathrm{y}_{\mathrm{i}}(\mathrm{k})}{\mathrm{T}_{\mathrm{s}}}
$$

So, the discrete-time system is concluded as: 
Int. J. Syst. Signal Control Eng. Appl., 13 (1): 1-17, 2020

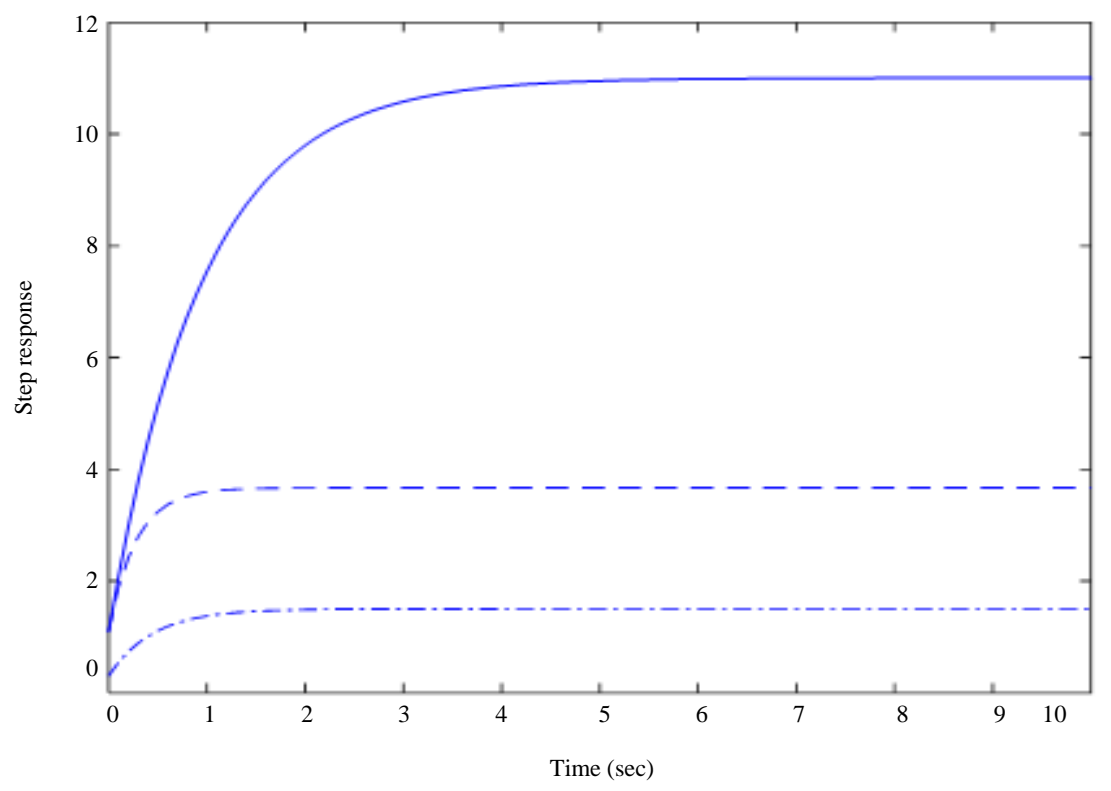

Fig. 1: Step responses, subsystem 1 (solid line), subsystem 2 (dash line), subsystem 3 (dash dot line)

$$
\left\{\begin{array}{c}
\mathrm{y}_{1}(\mathrm{k}+1)=\mathrm{a}_{1} \mathrm{y}_{1}(\mathrm{k})+0.1 \mathrm{y}_{1}(\mathrm{k})^{2}+0.7 \mathrm{u}_{1}(\mathrm{k})+0.4 \mathrm{u}_{2}(\mathrm{k}) \\
\mathrm{y}_{2}(\mathrm{k}+1)=\mathrm{a}_{2} \mathrm{y}_{2}(\mathrm{k})+0.2 \mathrm{y}_{2}(\mathrm{k})^{2}+\mathrm{u}_{2}(\mathrm{k})+0.1 \mathrm{u}_{2}(\mathrm{k}) \\
\mathrm{y}_{3}(\mathrm{k}+1)=\mathrm{a}_{3} \mathrm{y}_{3}(\mathrm{k})+0.1 \mathrm{y}_{3}(\mathrm{k})^{2}+0.2 \mathrm{u}_{3}(\mathrm{k})+0.1 \mathrm{u}_{2}(\mathrm{k})
\end{array}\right.
$$$$
\mathrm{W}(\mathrm{t})=\mathrm{gW}^{*}\left\{\begin{array}{cc}
0.01 & 0 \leq \mathrm{t}<2.5 \\
0.02 & 2.5 \leq \mathrm{t}<5 \\
-0.01 & 5 \leq \mathrm{t}<7.5 \\
0 & 7.5 \leq \mathrm{t}<10
\end{array}\right.
$$

where the sampling time is $\mathrm{T}_{\mathrm{s}}=0.1$ and:

$$
\alpha_{1}=0.9, \alpha_{2}=0.7, \alpha_{3}=0.8
$$

The step responses of subsystems are drawn in Fig. 1. According to the step responses the subsystem's settling times are approximately 6,2 , and 3 , respectively. So, the subsystem's optimal model horizons are:

$$
\mathrm{N}=\frac{\text { Setting Time }}{\mathrm{T}_{\mathrm{s}}} \rightarrow \mathrm{N}_{1}=60, \mathrm{~N}_{2}=20, \mathrm{~N}_{3}=30
$$

Note that in all simulations the subsystem's model horizons are considered $\mathrm{N}_{1}=60, \mathrm{~N}_{2}=20$ and $\mathrm{N}_{3}=$ 30 , respectively and also the subsystem's prediction and control horizons are considered 5 and 4 , respectively. The following constraint is imposed to control inputs:

$$
-4 \leq \mathrm{u}_{\mathrm{i}} \leq 4, \mathrm{i}=1,2,3
$$

The reference trajectory is considered as following equation: where the $g_{w}$ is the amplitude's coefficient of the reference trajectory. In first step of simulation we set the amplitude's coefficient as $\mathrm{g}_{\mathrm{w}}=10$ to consider the reference trajectory a little farther away from the origin (equilibrium point). Therefore, the subsystems' predicted outputs are illustrated in Fig. 2-4 using distributed DMC and proposed cooperative constrained DEDMC and DAGPC algorithms, respectively.

Since, in both DEDMC and DAGPC algorithms the mismatch between linearized and nonlinear models is compensated, so it is expected to obtain appropriate responses, the illustrated predicted output curves in Fig. 3 and 4 confirm this from the point of view of design criteria such as convergence, reference trajectory's tracking and stability. However, even though the reference trajectory is not too far from the origin, according to Fig. 2, the system has become unstable using the distributed DMC algorithm.

To further emphasize the effectiveness of proposed cooperative constrained DEDMC and DAGPC algorithms and compare them, the reference trajectory's amplitude is gradually increased; $g_{w}=50,80,110$ and simulation results are shown in Fig. 5-10. 
Int. J. Syst. Signal Control Eng. Appl., 13 (1): 1-17, 2020
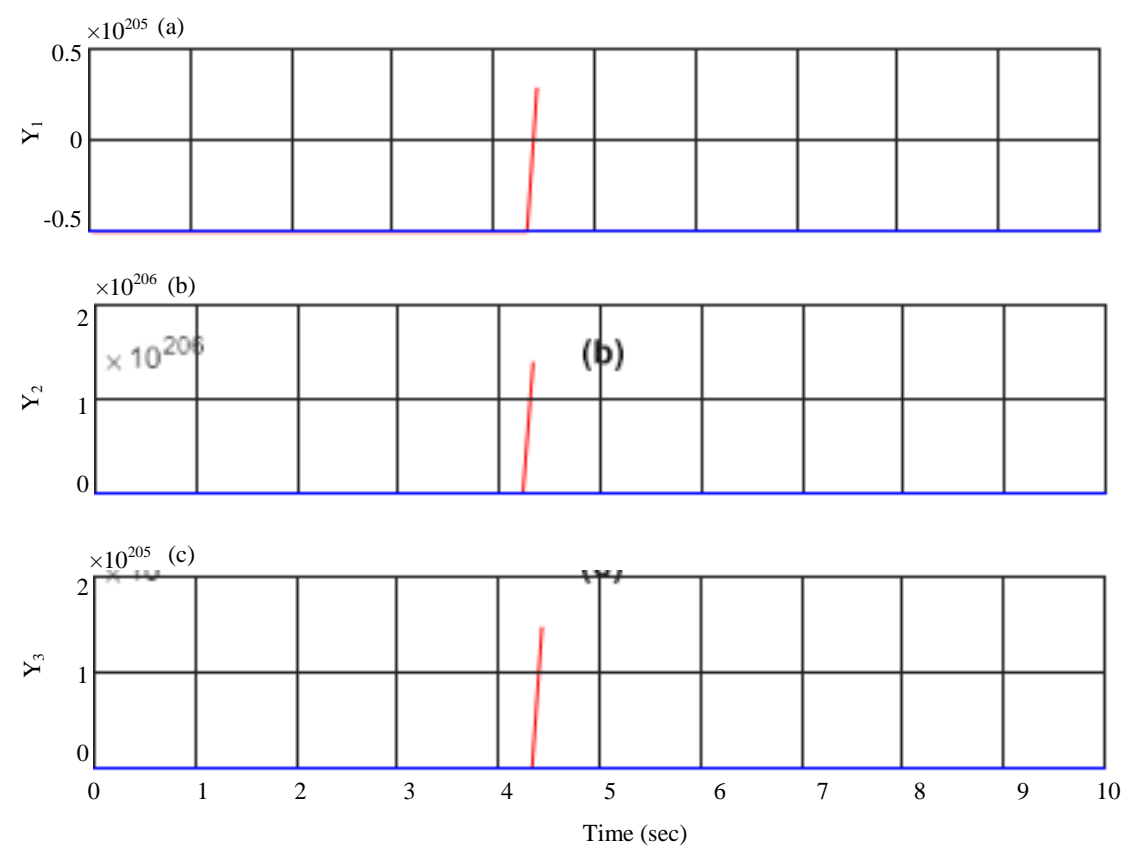

Fig. 2: The predicted outputs of nonlinear large scale system with $g_{w}=10$ and using cooperative distributed DMC algorithm; (a) Subsystem 1; (b) subsystem 2 and (c) subsystem 3
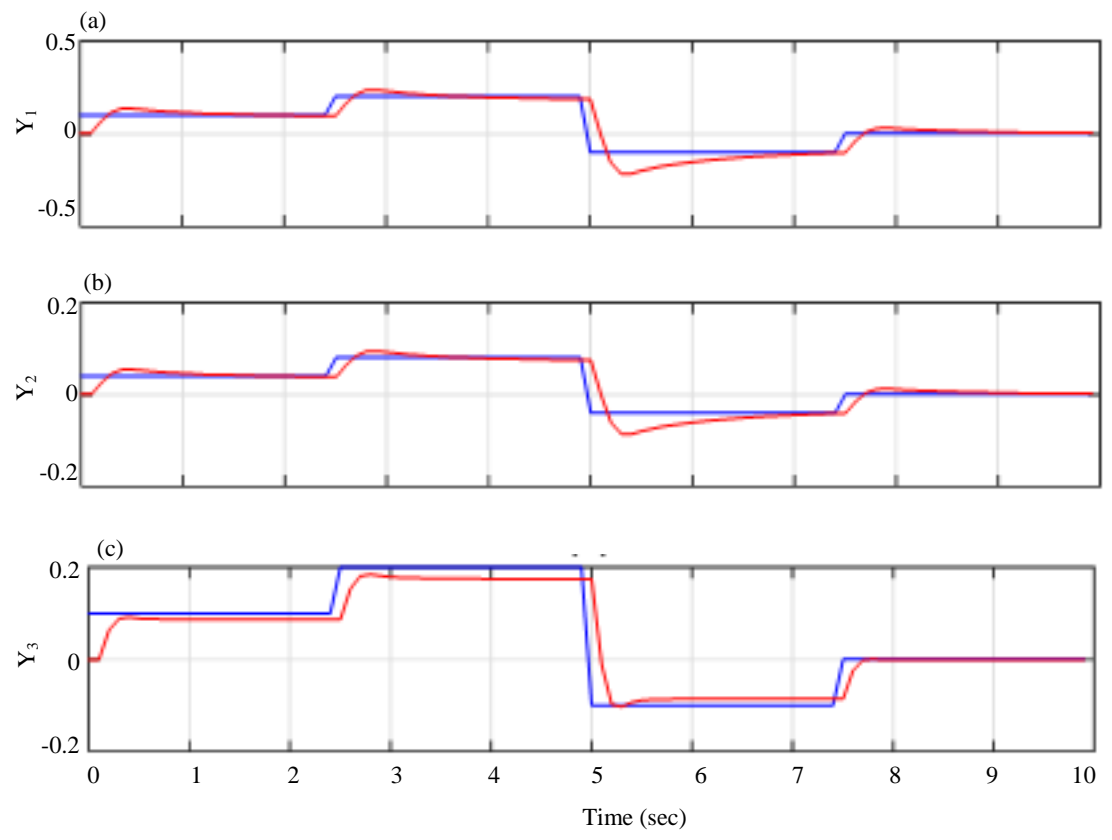

Fig. 3: The predicted outputs of nonlinear large scale system with $g_{w}=10$ and using proposed cooperative constrained DEDMC algorithm: (a) Subsystem 1; (b) subsystem 2; (c) subsystem 3

When the amplitude's coefficient is $g_{w}=50$, both methods have proper responses according to results in Fig. 5 and 6, however, according to Fig. 7 by increasing the $\mathrm{g}_{\mathrm{w}}$ to 80 some fluctuations are appeared when the DEDMC is applied while based on illustrated results in Fig. 8, the DAGPC shows appropriate predictions. The initial overshoots or undershoots in DAGPC's results is due to its online identification of the mismatch between linearized and nominal nonlinear models and after a short time that the identification of the linearized system's numerator and denominator polynomials is done the response becomes convergent. The usefulness of proposed 

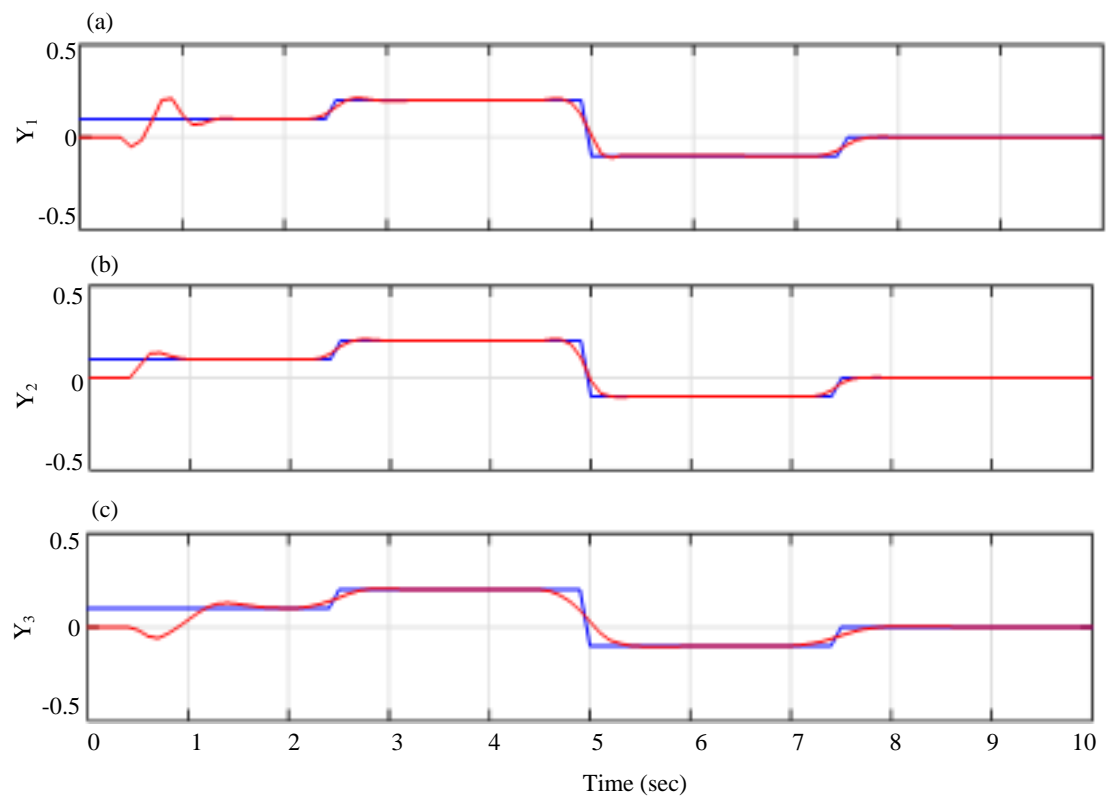

Fig. 4: The predicted outputs of nonlinear large scale system with $g_{w}=10$ and using proposed cooperative constrained DAGPC algorithm: (a) Subsystem 1; (b) subsystem 2; (c) subsystem 3
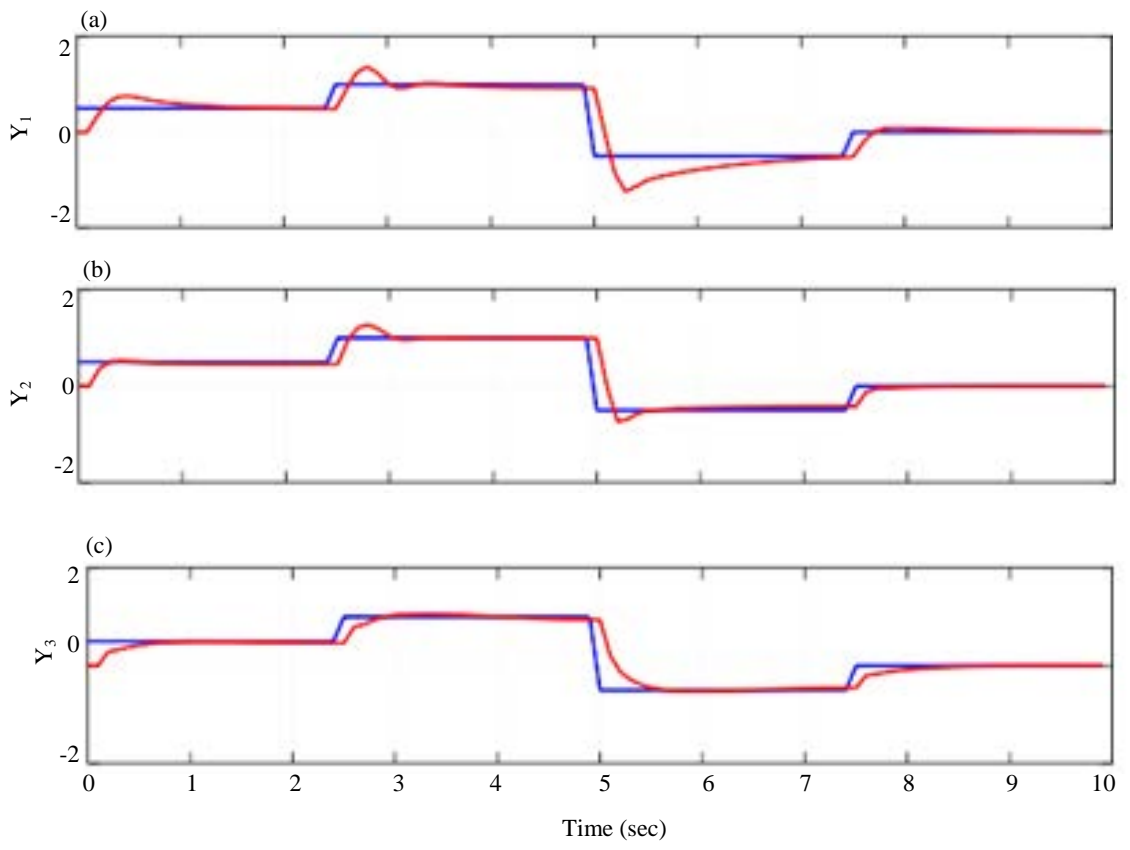

Fig. 5: The predicted outputs of nonlinear large scale system with $g_{w}=50$ and using proposed cooperative constrained DEDMC algorithm: (a) Subsystem 1; (b) subsystem 2; (c) subsystem 3

cooperative constrained DAGPC algorithm is more demonstrated when the reference trajectory is too farther away from the origin, hence to investigate this issue the amplitude's coefficient of the reference is increased to $g_{w}$ $=110$ and the simulation results are drawn in Fig. 9 and 10 using proposed cooperative constrained DEDMC and 
Int. J. Syst. Signal Control Eng. Appl., 13 (1): 1-17, 2020
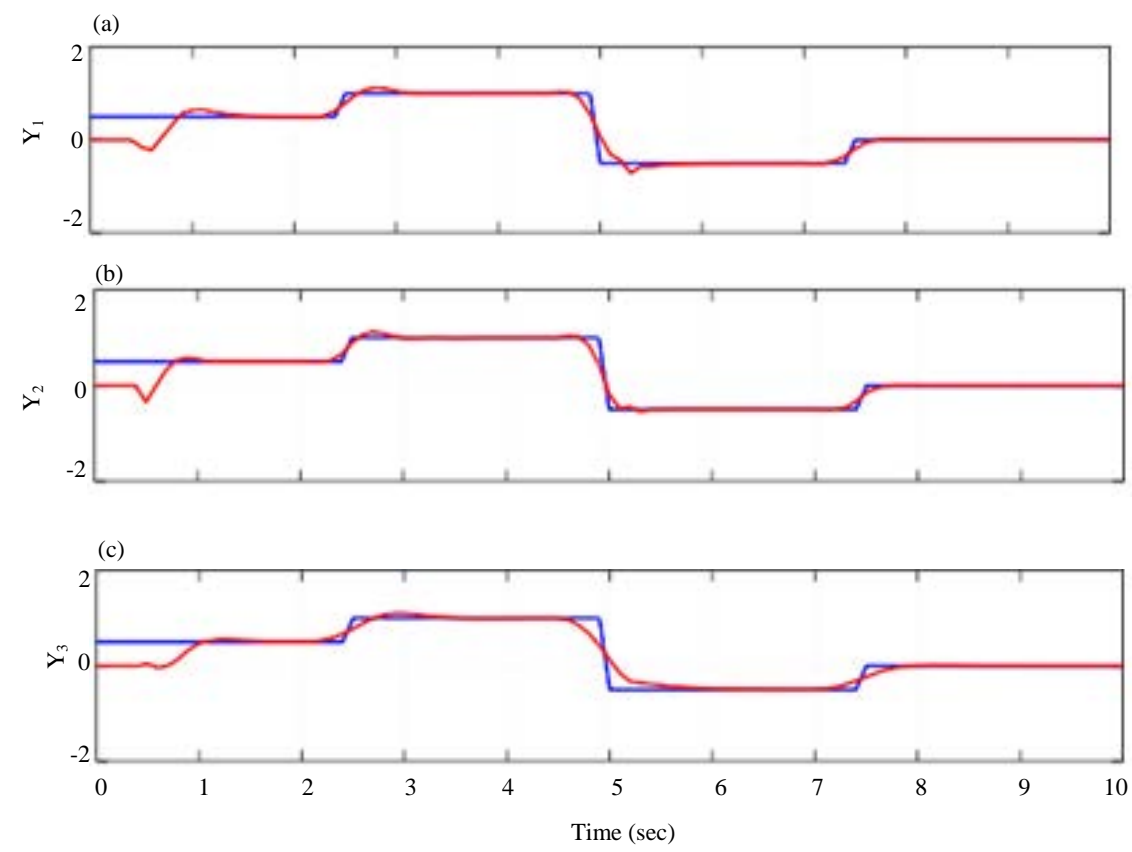

Fig. 6: The predicted outputs of nonlinear large scale system with $g_{w}=50$ and using proposed cooperative constrained DAGPC algorithm: (a) Subsystem 1; (b) subsystem 2; (c) subsystem 3
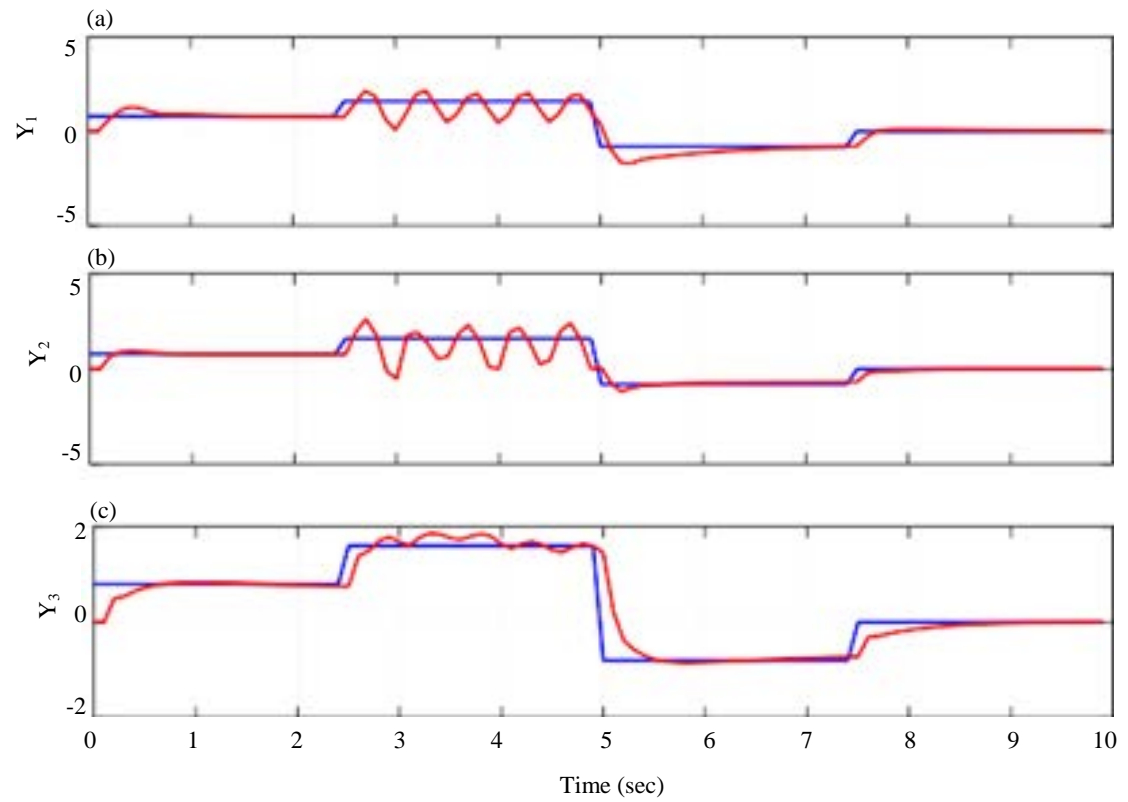

Fig. 7: The predicted outputs of nonlinear large scale system with $g_{w}=80$ and using proposed cooperative constrained DEDMC algorithm: (a) Subsystem 1; (b) subsystem 2; (c) subsystem 3

DAGPC algorithms, respectively. According to Fig. 9, the system has become unstable using the DEDMC algorithm while based on illustrated results in Fig. 10, the DAGPC shows appropriate predictions and closed-loop system is stable. Now the proposed approaches are examined when an uncertainty is applied. Assuming that in the fourth second of simulation, $\alpha 1, \alpha 2$ and $\alpha 3$ change as:

$$
\alpha_{1}^{\text {new }}=\alpha_{2}^{\text {new }}=\alpha_{1}^{\text {new }}=0.4
$$



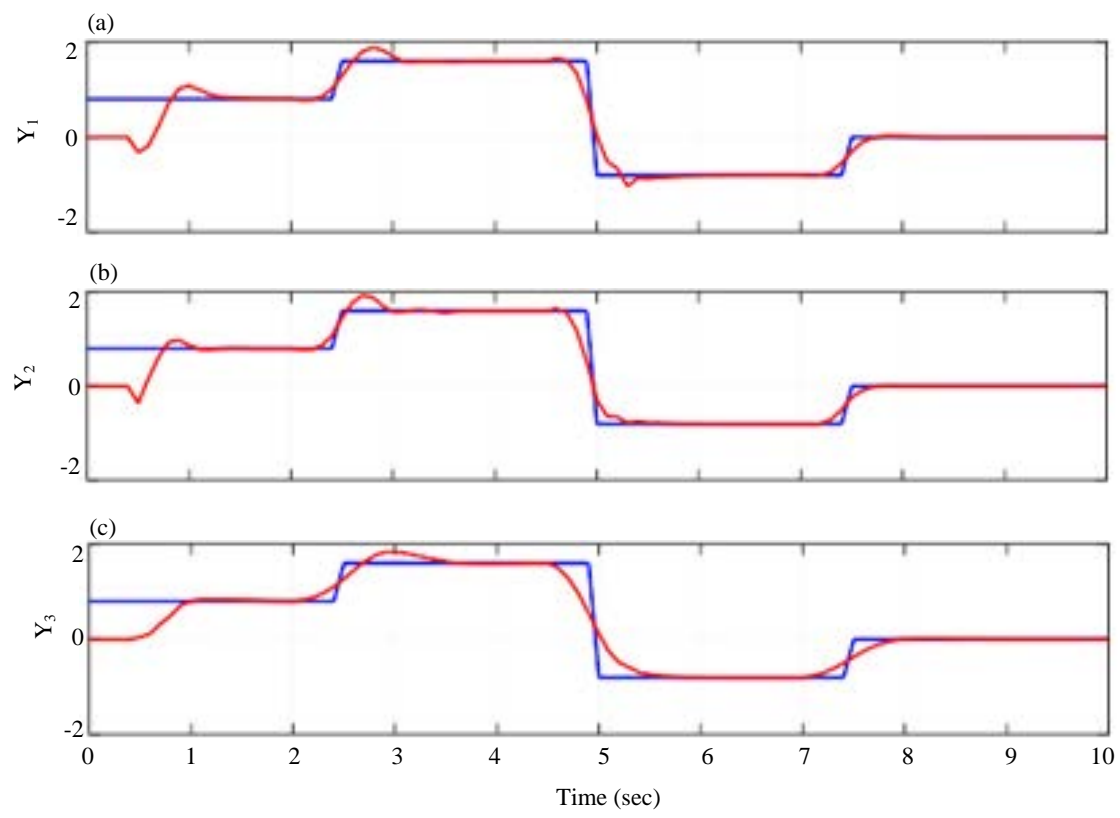

Fig. 8: The predicted outputs of nonlinear large scale system with $g_{w}=80$ and using proposed cooperative constrained DAGPC algorithm: (a) Subsystem 1; (b) subsystem 2; (c) subsystem 3
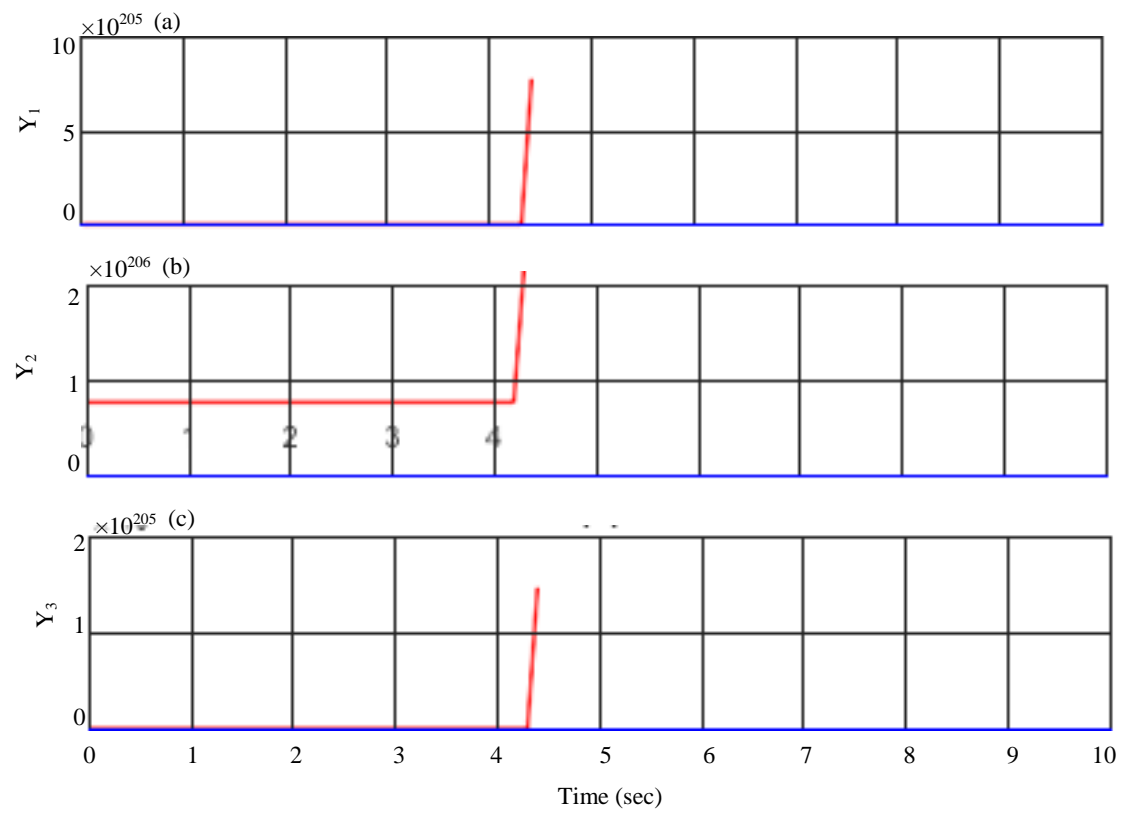

Fig. 9: The predicted outputs of nonlinear large scale system with $g_{w}=110$ and using proposed cooperative constrained DEDMC algorithm: (a) Subsystem 1; (b) subsystem 2; (c) subsystem 3

The simulation results are depicted in Fig. 11 and 12 with $\mathrm{g}_{\mathrm{w}}=50$. The results emphasizes the effectiveness of proposed algorithms in dealing with the uncertainty. Although the responses fluctuate when the uncertainties are imposed but they quickly converge.
All above mentioned results are yielded using the novel cooperative optimization strategy proposed in section 3 where each local controller solves a global cost function that is a convex combination of its own and its neighboring subsystem's cost functions. For example in 
Int. J. Syst. Signal Control Eng. Appl., 13 (1): 1-17, 2020

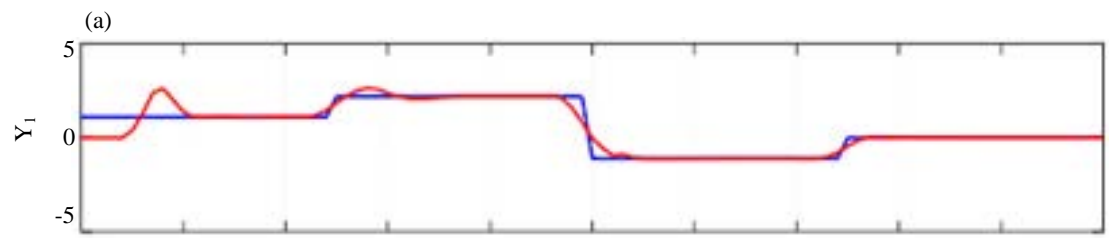

(b)
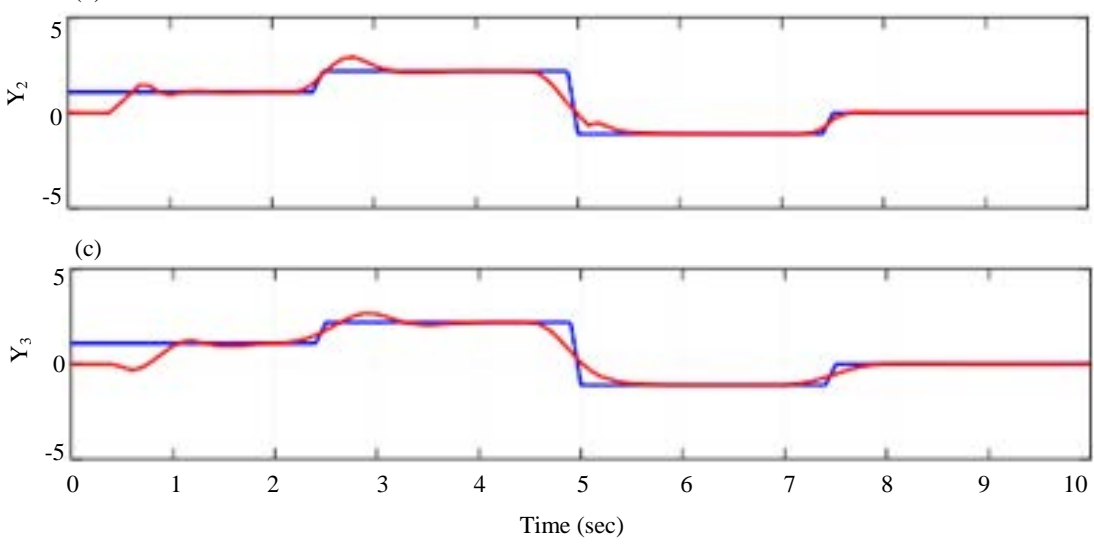

Fig. 10: The predicted outputs of nonlinear large scale system with $g_{w}=110$ and using proposed cooperative constrained DAGPC algorithm; (a) Subsystem 1; (b) subsystem 2; (c) subsystem 3
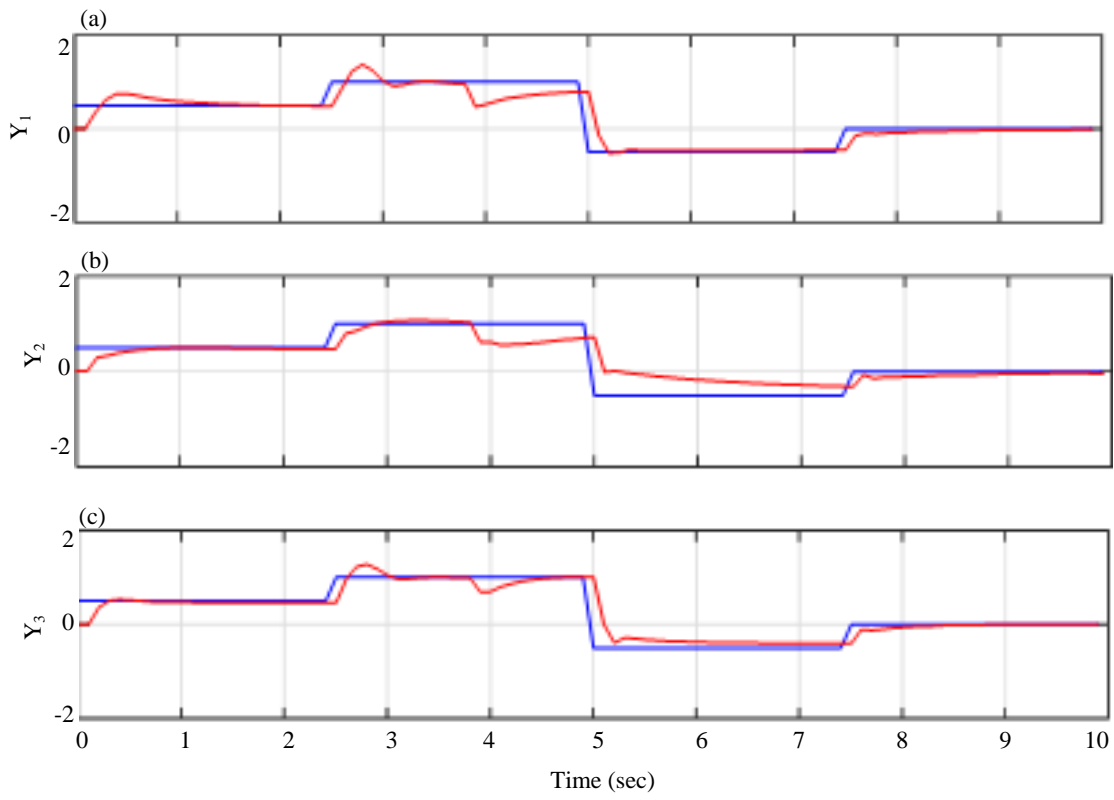

Fig. 11: The predicted outputs of nonlinear large scale system with imposed uncertainties and $g_{w}=50$ and using proposed cooperative constrained DEDMC algorithm: (a) Subsystem 1; (b) subsystem 2; (c) subsystem 3

large scale system which is analyzed in this section, subsystem 1 is neighbor to the subsystem 2 but not to the subsystem 3 . Thus, according to proposed optimization strategy, the global cost function which is minimized in local controller of subsystem 1 is defined as:

$$
\mathrm{j}=\alpha_{1} \mathrm{~J}_{1}+\mathrm{a}_{2} \mathrm{~J}_{2}, \alpha_{1}+\alpha_{2}=1
$$

While according to typical cooperative DMPCs, the global cost function is defined based on all three subsystems ${ }^{[1,4,20]}$. 
Int. J. Syst. Signal Control Eng. Appl., 13 (1): 1-17, 2020
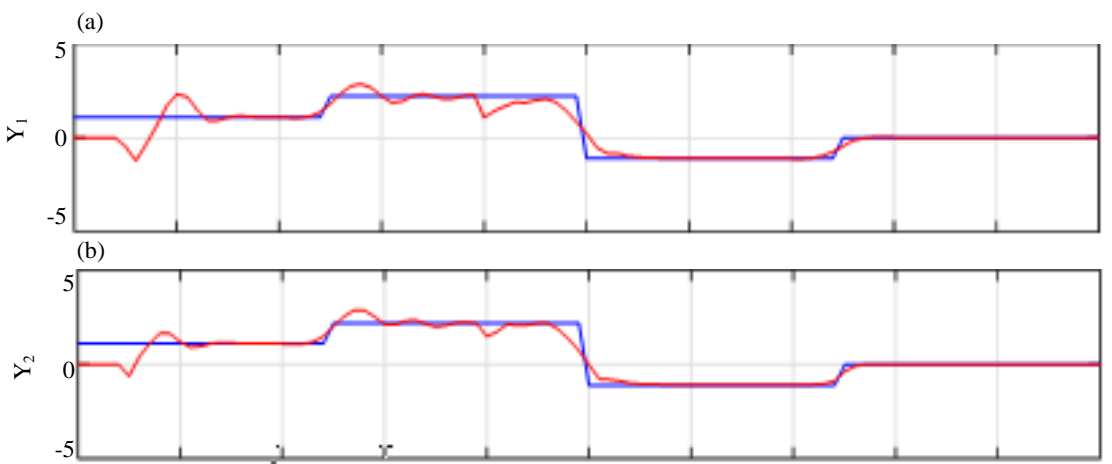

(c)

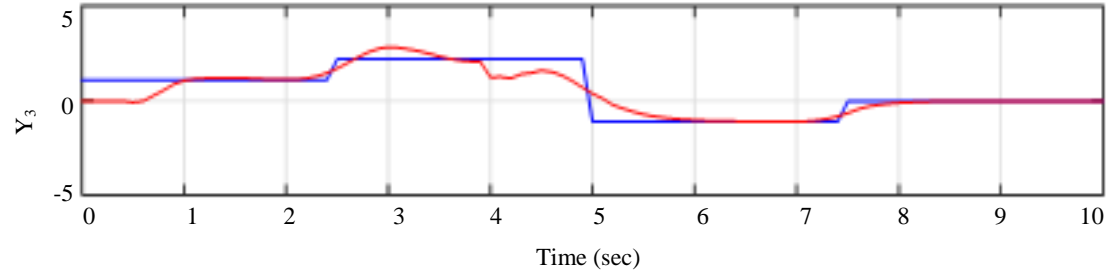

Fig. 12: The predicted outputs of nonlinear large scale system with imposed uncertainties and $g_{w}=50$ and using proposed cooperative constrained DAGPC algorithm: (a) Subsystem 1; (b) subsystem 2; (c) subsystem 3

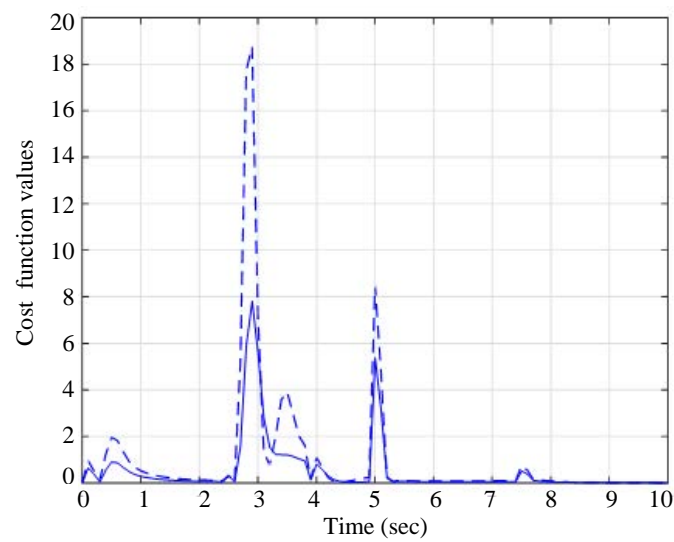

Fig. 13: The cost function values of the local controller of the uncertain subsystem 1 with $g_{w}=50$ and using typical (dash line) and proposed (solid line) cooperative optimization strategies

$$
\mathrm{J}=\mathrm{J}_{1}+\mathrm{J}_{2}+\mathrm{J}_{3}
$$

So, this is expected to decrease the control efforts, cost function values and convergence time using proposed cooperative optimization strategy. These criteria are examined by means of the following simulation results in which the proposed cooperative optimization strategy and DAGPC algorithm are used. The cost function values of the local controllers of the nonlinear large scale system with mentioned imposed uncertainties are illustrated in Fig. 13-15, respectively with $g_{w}=50$ and

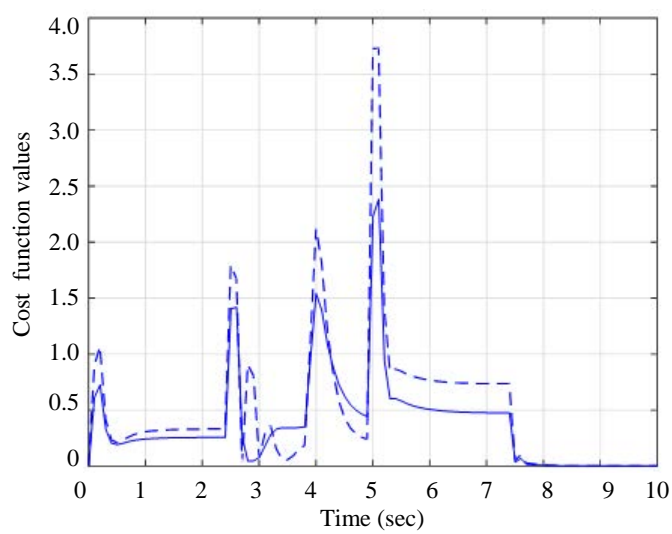

Fig. 14: The cost function values of the local controller of the uncertain subsystem 2 with $g_{w}=50$ and using typical (dash line) and proposed (solid line) cooperative optimization strategies

applying typical and proposed cooperative optimization strategies. It is cleared that the cost function values have decreased in proposed cooperative optimization strategy compared to typical one.

Figure 16 illustrates the predicted outputs of the nonlinear large scale system without uncertainty which are obtained using typical cooperative optimization strategy and DAGPC algorithm with $g_{w}=50$ and also Figure 6 illustrates the predicted outputs of the nonlinear large scale system without uncertainty using proposed cooperative optimization strategy and DAGPC algorithm with $g_{w}=50$. By comparing the results in Fig. 6 and 16, 


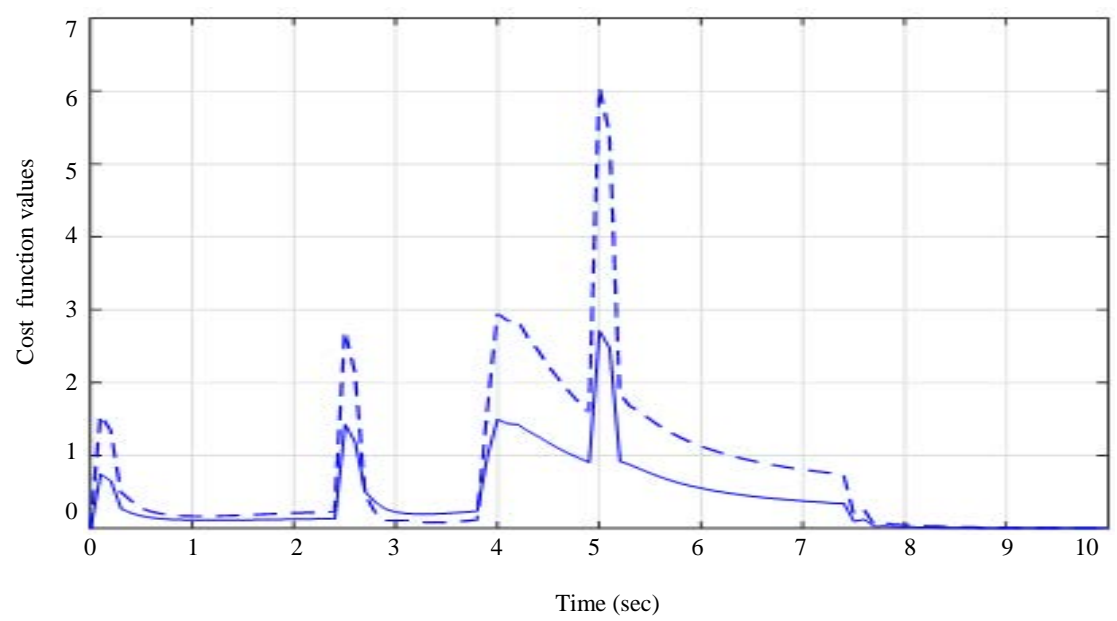

Fig. 15: The cost function values of the local controller of the uncertain subsystem 3 with $g_{w}=50$ and using typical (dash line) and proposed (solid line) cooperative optimization strategies
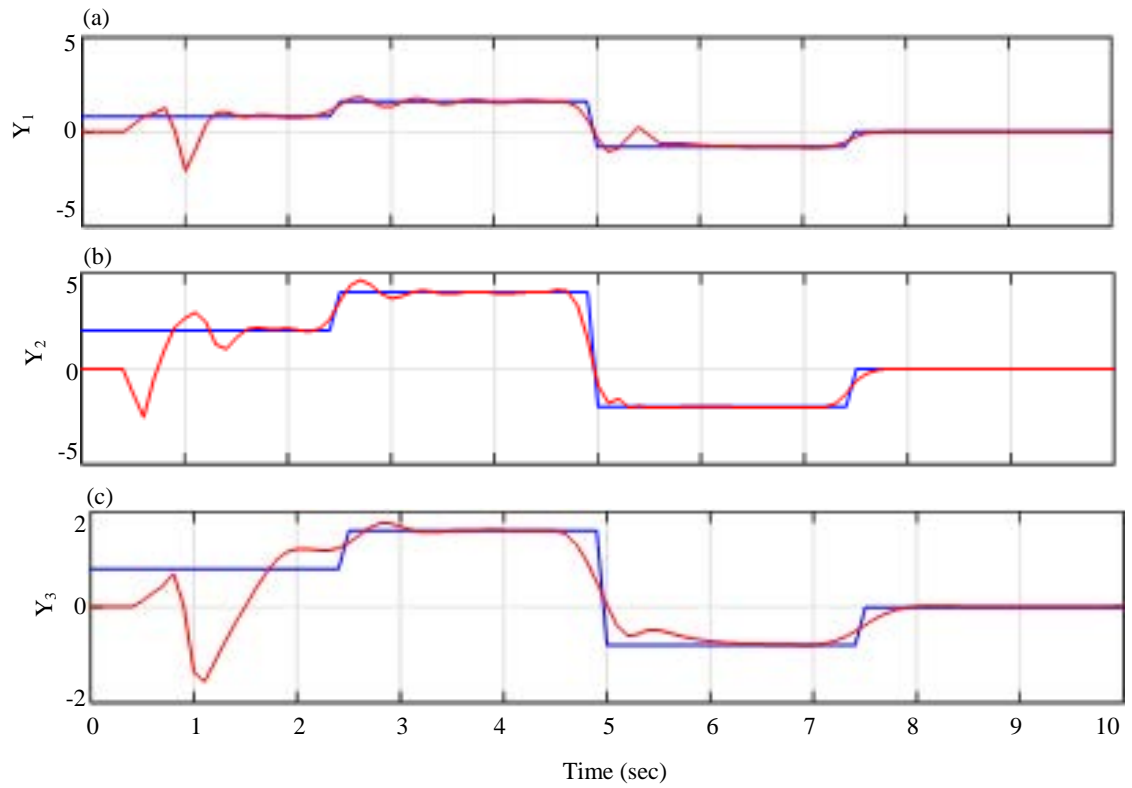

Fig. 16: The predicted outputs of nonlinear large scale system with $g_{w}=50$ and using typical cooperative DAGPC algorithm: (a) Subsystem 1; (b) subsystem 2; (c) subsystem 3

it is concluded that the time and quality of convergence has improved in proposed cooperative constrained DAGPC (Fig. 6) compared to typical one (Fig. 16).

\section{CONCLUSION}

In this manuscript a novel cooperative DMPC strategy is proposed which improves the centralized global cost function of each local controller. In proposed strategy, each local controller optimizes the global cost function that is a convex combination of its own and its neighboring subsystem's cost functions instead of the combination of its own and all other subsystem's cost functions. So, the computational burden of optimization, control efforts, cost function values and convergence time will be reduced compared to typical cooperative DMPC methods which are presented in other researches. Two linear distributed model predictive controllers; Distributed Extended Dynamic Matrix Control (DEDMC) and Distributed Adaptive Generalized Predictive Control (DAGPC) are presented that employs the proposed cooperative DMPC strategy to control the constrained 
coupled nonlinear large scale systems. The simulation results of a constrained nonlinear large scale system consisting of three interconnected nonlinear subsystems demonstrate the effectiveness of the proposed approaches. According to simulation results, the typical distributed linear algorithms like DMC leads to an unstable closed-loop response if the reference trajectory is far from the equilibrium point while this problem is partially solved using proposed DEDMC and completely solved using DAGPC algorithms even if the reference trajectory is too far from the equilibrium point.

\section{REFERENCES}

01. Christofides, P.D., R. Scattolini, D.M. De la Pena and J. Liu, 2012. D I stributed model predictive control: A tutorial review and future research directions. Comput. Chem. Eng., 51: 21-41.

02. Necoara, I. V. Nedelcu and I. Dumitrache, 2011. Parallel and distributed optimization methods for estimation and control in networks. J. Process Control, 21: 756-766.

03. Grancharova, A. T.A. Johansen and S. Olaru, 2018. Dual-mode distributed model predictive control of a quadruple-tank system. J. Chem. Technol. Metall., 53: 674-682.

04. Stewart, B.T., A.N. Venkat, J.B. Rawlings, S.J. Wright and G. Pannocchia, 2010. Cooperative distributed model predictive control. Syst. Control Lett., 59: 460-469.

05. Gao, Y., L. Dai, Y. Xia and Y. Liu, 2016. Distributed model predictive control for consensus of nonlinear second-order multi-agent systems. Int. J. Robust Nonlinear Control, 27: 830-842.

06. Sadati, N., M. Rahmani and M. Saif, 2014. Two-level robust optimal control of large-scale nonlinear systems. IEEE. Syst. J., 9: 242-251.

07. Zhao, M. and B. Ding, 2014. Distributed model predictive control for constrained nonlinear systems with decoupled local dynamics. ISA. Trans., 55: $1-12$.

08. Keviczky, T. F. Borrelli, K. Fregene, D. Godbole and G.J. Balas, 2008. Decentralized receding horizon control and coordination of autonomous vehicle formations. IEEE. Trans. Control Syst. Technol., 16: 19-33.

09. Liu, X. Y. Shi and D. Constantinescu, 2014. Distributed model predictive control of constrained weakly coupled nonlinear systems. Syst. Control Lett., 74: 41-49.
10. Dunbar, W.B., 2007. Distributed receding horizon control of dynamically coupled nonlinear systems. IEEE. Trans. Autom. Control, 52: 1249-1263.

11. Heidarinejad, M. J. Liu, D.M. De la Pena, J.F. Davis and P.D. Christofides, 2011. Multirate lyapunov-based distributed model predictive control of nonlinear uncertain systems. J. Process Control, 21: 1231-1242.

12. Li, H. and Y. Shi, 2013. Distributed model predictive control of constrained nonlinear systems with communication delays. Syst. Control Lett., 62: 819-826.

13. Liu, J., D.M. De la Pena and P.D. Christofides, 2009. Distributed model predictive control of nonlinear systems subject to asynchronous and delayed measurements. Automatica, 46: 52-61.

14. Liu, X., Y. Shi and D. Constantinescu, 2016. Robust distributed model predictive control of constrained continuous-time nonlinear systems using two-layer invariant sets. J. Dynamic Syst. Measur. Control, 138: $1-7$.

15. Li, H. and Y. Shi, 2014. Robust distributed model predictive control of constrained continuous-time nonlinear systems: A robustness constraint approach. IEEE. Trans. Autom. Control, 59: 1673-1678.

16. Zheng, Y., S.E. Li, K. Li, F. Borrelli and J.K. Hedrick, 2016. Distributed model predictive control for heterogeneous vehicle platoons under unidirectional topologies. IEEE. Trans. Control Syst. Technol., 25: 899-910.

17. Abokhatwa, S.G. and R. Katebi, 2013. Sequential distributed model predictive control for state-dependent nonlinear systems. Proceedings of the IEEE International Conference on Systems, Man and Cybernetics, October 13-16, 2013, IEEE, Manchester, UK, pp: 565-570.

18. Liu, X., Y. Shi and D. Constantinescu, 2017. Robust distributed model predictive control of constrained dynamically decoupled nonlinear systems: A contraction theory perspective. Syst. Control Lett., 105: 84-91.

19. Esfahani, N.R. and K. Khorasani, 2015. A distributed Model Predictive Control (MPC) fault reconfiguration strategy for formation flying satellites. Int. J. Control, 89: 960-983.

20. Stewart, B.T., S.J. Wright and J.B. Rawlings, 2010. Cooperative distributed model predictive control for nonlinear systems. J. Process Control, 21: 698-704.

21. Camacho, E.F. and C. Bordons, 2004. Model Predictive Control. 2nd Edn., Springer-Verlag, Berlin Heidelberg, ISBN: 1852336943, pp: 1-80. 